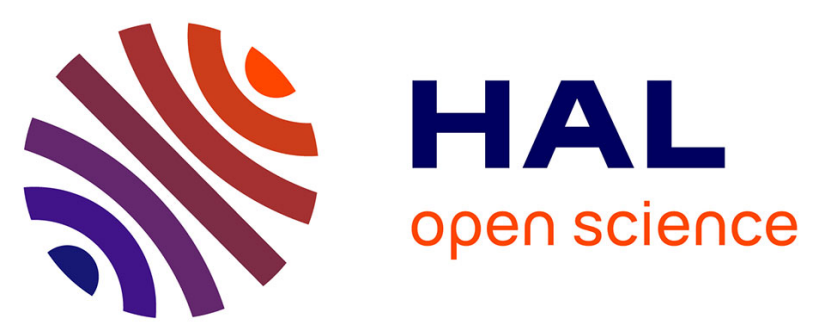

\title{
Temperature dependence of ${ }^{1} H$ paramagnetic chemical shifts in actinide complexes, beyond Bleaney's theory: The $\mathrm{An}^{V I} \mathrm{O} \_2^{2+}-$ Dipicolinic AcidcComplexes $(\mathrm{An}=\mathrm{Np}$, $\mathrm{Pu})$ as an Example
}

Matthieu Autillo, Md. Ashraful Islam, Julie Héron, Laetitia Guérin, Eléonor Acher, Christelle Tamain, Marie-Claire Illy, Philippe Moisy, Eric Colineau, Jean-Christophe Griveau, et al.

\section{To cite this version:}

Matthieu Autillo, Md. Ashraful Islam, Julie Héron, Laetitia Guérin, Eléonor Acher, et al.. Temperature dependence of ${ }^{1} H$ paramagnetic chemical shifts in actinide complexes, beyond Bleaney's theory: The $\mathrm{An}^{V I} \mathrm{O} \_2^{2+}$ - Dipicolinic AcidcComplexes $(\mathrm{An}=\mathrm{Np}, \mathrm{Pu})$ as an Example. Chemistry - A European Journal, 2021, 27 (24), pp.7138-7153. 10.1002/chem.202005147 . hal-03215097

\author{
HAL Id: hal-03215097 \\ https://hal.science/hal-03215097
}

Submitted on 16 Nov 2021

HAL is a multi-disciplinary open access archive for the deposit and dissemination of scientific research documents, whether they are published or not. The documents may come from teaching and research institutions in France or abroad, or from public or private research centers.
L'archive ouverte pluridisciplinaire HAL, est destinée au dépôt et à la diffusion de documents scientifiques de niveau recherche, publiés ou non, émanant des établissements d'enseignement et de recherche français ou étrangers, des laboratoires publics ou privés. 


\title{
Temperature dependence of ${ }^{1} \mathrm{H}$ paramagnetic chemical shifts in actinide complexes, beyond Bleaney's theory. The $\mathrm{An}^{\mathrm{VI}} \mathrm{O}_{2}^{2+}-\mathrm{DPA}$ complexes $(\mathrm{An}=\mathrm{Np}, \mathrm{Pu})$ as an example.
}

\author{
Matthieu Autillo[a] \#, Md. Ashraful Islam ${ }^{[b]}$, Julie Héron ${ }^{[c]}$, Laetitia Guérin ${ }^{[a]}$, Eleonor Acher ${ }^{[a]}$, Christelle \\ Tamain $^{[a]}$, Marie-Claire Illy ${ }^{[a]} £$, Philippe Moisy ${ }^{[a]}$, Eric Colineau ${ }^{[d]}$, Jean-Christophe Griveau ${ }^{[d]}$, Claude \\ Berthon ${ }^{*}[a]$ and Hélène Bolvin ${ }^{*}[\mathrm{~b}]$
}

[a] CEA, DES, ISEC, DMRC, Univ Montpellier, Marcoule, France.

E-mail: claude.berthon@cea.fr.

[b] Laboratoire de Chimie et Physique Quantiques, CNRS, Université Toulouse III, 118 route de Narbonne, 31062 Toulouse, France.

E-mail: bolvin@irsamc.ups-tlse.fr.

[c] \$ Hylleraas Centre for Quantum Molecular Sciences, Department of Chemistry, University of Oslo, P.O. Box 1033, Blindern, 0315 Oslo, Norway.

[d] European Commission Joint Research Centre (JRC), Karlsruhe, Germany.

\# These authors contributed equally to this work.

\& actual address: Planitec, CEA Marcoule, 30207 Bagnols/Cèze, France.

Supporting information for this article is given via a link at the end of the document

\begin{abstract}
Actinide $+\mathrm{VI}$ complexes $\left(\mathrm{An}^{\mathrm{VI}}=\mathrm{U}^{\mathrm{VI}}, \mathrm{Np}^{\mathrm{VI}}\right.$ and $\left.\mathrm{Pu}^{\mathrm{VI}}\right)$ with dipicolinic acid derivatives were synthesized and characterized by powder XRD, SQUID magnetometry and NMR spectroscopy. In addition, $\mathrm{Np}^{\mathrm{VI}}$ and $\mathrm{Pu}^{\mathrm{VI}}$ complexes were described by first principles CAS based and two-component spin-restricted DFT methods. The analysis of the ${ }^{1} \mathrm{H}$ paramagnetic NMR chemical shifts for all protons of the ligands according to the $\mathrm{X}$-rays structures shows that the Fermi contact contribution is negligible in agreement with spin density determined by unrestricted DFT. The magnetic susceptibility tensor is determined by combining SQUID, pNMR shifts and Evans' method. The SO-RASPT2 results fit well the experimental magnetic susceptibility and pNMR chemical shifts. The role of the counterions in the solid phase is pointed out; their presence impacts the magnetic properties of the $\mathrm{Np}^{\mathrm{VI}}$ complex. The temperature dependence of the pNMR chemical shifts has a strong $1 / T$ contribution, contrarily to Bleaney's theory for lanthanide complexes. The fitting of the temperature dependence of the pNMR chemical shifts and SQUID magnetic susceptibility by a two-Kramers-doublet model for the $\mathrm{Np}^{\mathrm{VI}}$ complex and a non-Kramers-doublet model for the $\mathrm{Pu}^{\mathrm{VI}}$ complex allows for the experimental evaluation of energy gaps and magnetic moments of the paramagnetic center.
\end{abstract}

\section{Introduction}

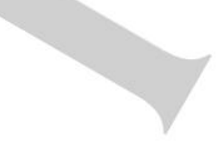

Paramagnetic NMR (pNMR) using lanthanide + III $\left(\mathrm{Ln}^{\mathrm{III}}\right)$ cations is of huge importance in order to provide structural information on metal-ligand complexes in solution. ${ }^{[1-2]}$ The analysis of lanthanide induced shifts (LIS) have been successfully used to this purpose especially for applications to biological systems. ${ }^{[3-4]}$ In the nuclear fuel cycle research area, the possibility of using NMR experiments is not fully exploited as revealed by the few articles on the subject, ${ }^{[5-11]}$ while it could represent a powerful tool for the characterization of solution species. Uranium is by far the most abundant and involved cation in the different processes of the nuclear fuel industry as well as in the environmental radiotoxicity fields and its selective separation from various media remains of paramount importance. In aqueous systems, it is well known that uranium exist as a linear dioxo cation $\left[\mathrm{U}^{\mathrm{VI}} \mathrm{O}_{2}\right]^{2+}$, which enforce the ligand coordination only in the equatorial plane. ${ }^{[12]}$ As indicate by its electronic configuration $\left(5 f^{0}\right)$, the $\left[\mathrm{U}^{\mathrm{VI}} \mathrm{O}_{2}\right]^{2+}$ cation is diamagnetic and is not suitable for pNMR applications. As it has been done for biological system study, this problem can be solved by substituting the uranyl cation with the isostructural paramagnetic $\left[\mathrm{Np}^{\mathrm{VI}} \mathrm{O}_{2}\right]^{2+}\left(5 f^{1}\right)$ or $\left[\mathrm{Pu}^{\mathrm{VI}} \mathrm{O}_{2}\right]^{2+}\left(5 f^{2}\right)$ cations. In this sense, it appears of particular interest to examine the possibility to use paramagnetic chemical shift equations to investigate the $\mathrm{An}^{\mathrm{VI}}$ coordination chemistry by NMR spectroscopy in solution.

The presence of a paramagnetic center induces on the NMR spectrum of an atom $K$ situated on the ligand an additional shift $\delta_{K}^{p}$ with respect to a diamagnetic analog. This shift breaks down into two terms

$$
\delta_{K}^{p}=\delta_{K}^{p c}+\delta_{K}^{c}
$$

in which $\delta_{K}^{p c}$ and $\delta_{K}^{c}$ are the pseudocontact (dipolar) and the Fermi contact components, respectively. The later arises from the spin density on the ligand nucleus $K$. It is a consequence of the spin delocalization from the paramagnetic cation though the metal-ligand bonds and spin-polarization due to the presence of extra unpaired electrons. ${ }^{[13]}$ Within the point-dipole approximation, ${ }^{[14]}$ the pseudocontact shift $\delta_{K}^{p c}$ describes the 
through-space magnetic dipolar interaction. Bertini et al. have shown that it can be expressed, for an axial system, as

$$
\delta_{K}^{p c}=\frac{10^{6}}{12 \pi N_{A}} \Delta \chi_{a x} G_{K}
$$

where

$$
\Delta \chi_{a x}=\chi_{z z}-\frac{\chi_{x x}+\chi_{y y}}{2}
$$

is the axial anisotropy of the magnetic susceptibility tensor $\chi$ in $\mathrm{m}^{3} \mathrm{~mol}^{-1} ; \chi_{x x}, \chi_{y y}$ and $\chi_{z z}$ are the three principal components of the $\chi$ tensor and $N_{A}$ is the Avogadro constant. The last term is the geometrical factor $G_{K}=\left(3 \cos ^{2} \theta_{K}-1\right) r_{K}^{-3}$, which characterizes the relative position of the nucleus of interest $K$ to the cation, $r_{K}$ is the metal-nucleus distance, $\theta_{K}$ is the azimuthal angle about the symmetry axis. This equation supposes an axial symmetry, and therefore $\chi_{x x}$ and $\chi_{y y}$ to be similar. In the present case, the $z$ axis is along the $\mathrm{An}^{\mathrm{VI}}-\mathrm{O}_{\mathrm{yl}}$ bond and $\chi_{z z}$ will be denoted as $\chi_{\|} \cdot x$ and $y$ form the equatorial plane and one defines $\chi_{\perp}=\frac{\chi_{x x}+\chi_{y y}}{2}$. The Fermi contact contribution strongly affects the closest nuclei from the metal center and gradually decreases with the number of bonds between the paramagnetic cation and the nucleus studied by NMR. ${ }^{[1]}$ It results that the pNMR shifts of nuclei far from the paramagnetic cation are dominated by the pseudocontact contribution while in intermediate position, the two contributions are similar in magnitude.

The evaluation of $\mathrm{An}^{\mathrm{VI}}$ chemical structures from their paramagnetic chemical shifts supposes to properly discriminate between the pseudocontact and Fermi contact contributions. To achieve this task, several methods were developed for $\mathrm{Ln}^{\text {III }}$ complexes. The most common methods summarized at first by Reilley ${ }^{[15-16]}$ relies upon proportionating the measured shifts in an isostructural series with the theoretical $S_{z}$ and $C^{D}$ parameters tabulated in the literature for each metal. ${ }^{[17-21]}$ Beyond the isostructurality, these methods assume the knowledge of the $S_{Z}$ and $C^{D}$ parameters and that the ligand field as well as the hyperfine coupling constant are constant along the series. Even if some limits have been pointed out, ${ }^{[22-23]}$ they have been widely applied to $\mathrm{Ln}^{\mathrm{III}}$ complexes. Our recent attempt to apply such methods in the $\left[\mathrm{An}^{\mathrm{III}}(\mathrm{DPA})_{3}\right]^{3-}$ series $(\mathrm{DPA}=2,6$-dipicolinate) was unsuccessful because of the previous conditions not completely fulfilled. ${ }^{[7]}$ In actinyl complexes, the presence of the $y l$ bond makes those ions even more unsuitable to be treated by ligand field theory and the whole series is not available since only two paramagnetic cations are easily stabilized in solution.

Consequently, we turned towards the second by exploiting the temperature dependence of the actinide induced shifts (AIS). This less famous method for the LIS study relies on the difference in the temperature dependence of the two contributions. According to Bleaney's theory, ${ }^{[17-18,24]}$ the contact and dipolar contributions behave as $T^{-1}$ and $T^{-2}$, respectively within a 10 to $20 \%$ accuracy. ${ }^{25]}$ Significant deviations from this theory were revealed which made its use more controversial ${ }^{26]}$ and we recently showed ${ }^{[7]}$ that this theory was not valid in the $\left[\mathrm{An}^{\mathrm{III}}(\mathrm{DPA})_{3}\right]^{3-}$ series. Indeed, Bleaney's formulation is based on the vanishing of the $T^{-1}$ term of the dipolar contribution because the splitting of the Stark levels arising from free ion is of the order of magnitude of the room temperature energy. In actinide complexes, the interpretation of magnetic properties is more difficult than in lanthanide complexes. The rather large radial extension of the An $5 f$ shell leads to non-negligible covalent effects with the ligands giving rise to large ligand fields. This makes the basic hypothesis of Bleaney's theory not adequate to describe actinide complexes and leads to its breakdown when applied to those complexes. However, this approach remains of great interest to exploit the AIS as it could provide a clear separation of the pseudocontact and Fermi contact contributions when properly applied.

The aim of this work is to analyze and model the ${ }^{1} \mathrm{H}$ paramagnetic chemical shifts of $\left[\mathrm{An}^{\mathrm{VI}} \mathrm{O}_{2}\right]^{2+}$ complexes. To the best of our knowledge, it is the first exploitation of ${ }^{1} \mathrm{H}$ AIS in $\left[\mathrm{An}^{\mathrm{VI}} \mathrm{O}_{2}\right]^{2+}$ complexes while one study reports attempt to separate the pseudocontact and Fermi contact contributions of ${ }^{13} \mathrm{C}$ pNMR shifts in $\left[\mathrm{AnO}_{2}\left(\mathrm{CO}_{3}\right)_{3}\right]^{4-}$ complexes. ${ }^{[27]}$ As a natural benchmark, we chose the DPA ligand. This ligand coordinated to $\mathrm{Ln}^{\mathrm{III}}$ has served as a reference for many studies for LIS as recently reviewed by Peters et al. ${ }^{[28]}$, starting with Bleaney in the 70 's ${ }^{[18]}$ then with Reilley and Desreux. ${ }^{[16,29]}$ We have recently studied the $\left[\mathrm{An}^{\mathrm{III}}(\mathrm{DPA})_{3}\right]^{3-}$ series and we now extend this work with $\left[\mathrm{An}^{\mathrm{VI}} \mathrm{O}_{2}\right]^{2+}-\mathrm{DPA}$ derivatives. The synthesis of the $\left[\mathrm{An}^{\mathrm{VI}} \mathrm{O}_{2}\right]^{2+}-\mathrm{DPA}$ complexes (with $\mathrm{An}^{\mathrm{VI}}=\mathrm{U}^{\mathrm{VI}}, \mathrm{Np}^{\mathrm{VI}}, \mathrm{Pu}^{\mathrm{VI}}$ and $\mathrm{Am}^{\mathrm{VI}}$ ) has been previously reported in aqueous solution. ${ }^{\left[{ }^{30]}\right.}$ For a better characterization of the magnetic properties of the paramagnetic center, SQUID measurements on solid $\mathrm{Li}_{2} \mathrm{An}^{\mathrm{VI}} \mathrm{O}_{2}$ (DPA $)_{2} \cdot 2 \mathrm{H}_{2} \mathrm{O}$ compounds, magnetic susceptibility measurements in solution and ab initio calculations complete this study.

The modelling of pNMR shifts by quantum chemical tools often relies on the calculation of Spin Hamiltonian parameters, in terms of the $\mathbf{g}$ and HFC $\mathbf{A}_{K}$ tensors, and is usually performed by using DFT for transition metal complexes. ${ }^{[31-36]}$ The wave function based method SO-CASPT2 has demonstrated its capability to provide a good estimate of the magnetic properties of actinide complexes, permitting a balanced description of the relativistic and correlation effects, both playing key roles in those complexes. ${ }^{[37-39]}$ Autschbach et al. described recently the pNMR shifts of actinyl tris-carbonate complexes using a first principles approach based on the RASSCF method. ${ }^{[9]}$ the dipolar contribution is estimated from the SO-RASPT2 description of the electronic properties of the paramagnetic center and is compared to two-component spin-restricted SO-ZORA DFT method. 
WILEY-VCH

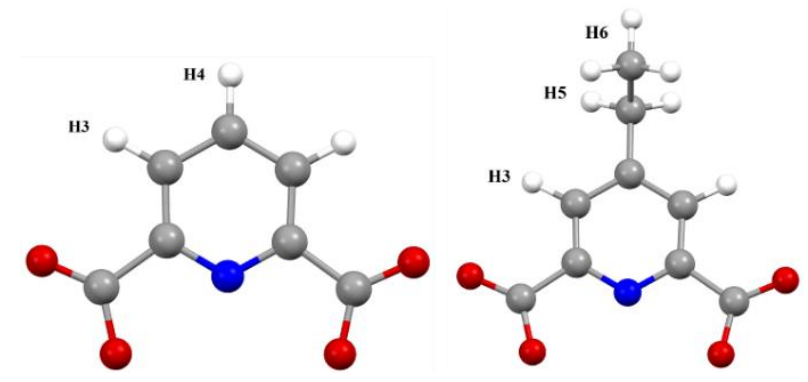

Figure 1: DPA and Et - DPA ligands with the numbering of the hydrogen atoms. Color code: $\mathrm{H}$ : white, C: grey, $\mathrm{N}$ : blue, O: red.

The temperature dependence of pNMR chemical shifts has been very early modelled. In transition metal complexes, McConnell and Robertson attributed the pseudocontact shift to the anisotropy of the $\mathbf{g}$ tensor and the temperature dependence was predicted to be as $T^{-1} \cdot{ }^{[40]}$ Kurland and McGarvey used the van Vleck equation to analyze the $\mathrm{T}$ variation, which led to a more complex behavior. ${ }^{[13]}$ Bleaney derived a high temperature approximation for the lanthanide complexes which led to a $T^{-2}$ behavior, related to the crystal field parameters of $2^{\text {nd }}$ order. The $T^{-1}$ term vanishes due to the isotropic magnetic response of the lanthanide at room temperature. Further $T^{-n}$ terms should be taken into account. ${ }^{[20,24]}$ McGarvey proposed one modelization of the $\mathrm{T}$ behavior of AIS in the case of $\mathrm{An}^{\mathrm{IV}}$ methyl borohydrides complexes. ${ }^{[41]}$

Recently, Soncini and van den Heuvel proposed a general theoretical framework for the derivation of pNMR chemical shifts. ${ }^{[42]}$ This equation was used by Martin and Autschbach to analyze the effect of the Zero Field Splitting on the temperature dependence, using the Spin Hamiltonian formalism. ${ }^{[43]}$ We follow this frame in the present work, by applying Soncini equation to systems described as a two-Kramers-doublets system for the $\mathrm{Np}^{\mathrm{VI}}$ complex, and a non-Kramers-doublet system for the $\mathrm{Pu}^{\mathrm{VI}}$ complex. The model parameters are determined by fitting the experimental curves and compared to their $a b$ initio values. The analysis of the different $T^{-n}$ allows an evaluation of the electronic parameters of the paramagnetic center, both energy gaps and magnetic moments. The magnetic susceptibility tensor is fully characterized from both the isotropic component characterized by Evans method or SQUID and the anisotropic one deduced from the AIS. The comparison between the solid state and the solution magnetic susceptibility tensors evidences the role of the counterions.

\section{Results and Discussion}

Crystal structure and geometry optimization. Powder XRD analyses were performed at room temperature on the $\mathrm{Li}_{2} \mathrm{An}^{\mathrm{VI}} \mathrm{O}_{2}$ (DPA) $)_{2} \cdot 2 \mathrm{H}_{2} \mathrm{O}$ compounds isolated from aqueous solution to check their purity. Good agreements were observed between experimental $\mathrm{Li}_{2} \mathrm{An}^{\mathrm{VI}} \mathrm{O}_{2}$ (DPA $)_{2} \cdot 2 \mathrm{H}_{2} \mathrm{O}$ and XRD patterns calculated from $X$-ray structures. ${ }^{[30]}$ Results of the fitting procedure reveal small distortions of the unit cells (as shown Table SI-1) while the profile-matching (as presented in Figure SI1 for the neptunium phase) clearly show that all the $\mathrm{An}^{\mathrm{VI}}$ compounds are single-phased.

The structure of $\left[\mathrm{U}^{\mathrm{VI}} \mathrm{O}_{2}(\mathrm{Et}-\mathrm{DPA})_{2}\right]^{2-}$ was determined by DFT geometry optimization in order to determine the ethyl chain position (cf Figure SI-3). The first coordination sphere bond distances $\left(\mathrm{U}^{\mathrm{VI}}=\mathrm{O}_{\mathrm{yl}}, \mathrm{U}^{\mathrm{VI}}-\mathrm{O}\right.$ and $\left.\mathrm{U}^{\mathrm{VI}}-\mathrm{N}\right)$ are reported in Table 1 and compared to SC-XRD data. ${ }^{[30]}$ The geometric parameters $G_{K}$ of Eq. 2 are calculated from the DFT and SC-XRD structures taking the $\mathrm{An}^{\mathrm{VI}}=\mathrm{O}_{\mathrm{yl}}$ bond as the $z$ axis.

The ${ }^{1} \mathrm{H}$ nuclei of the DPA and Et - DPA ligands are numbered as presented in Figure 1 and are averaged on chemically equivalent positions. The computed metal-ligand distances are overestimated as compared to the $\mathrm{X}$-rays structures. The $\mathrm{U}^{\mathrm{VI}}=$ $\mathrm{O}_{\mathrm{yl}}$ bond is overestimated by $0.05 \AA$. The $\mathrm{U}^{\mathrm{VI}}-0$ distance is close to the experimental one while $\mathrm{U}^{\mathrm{VI}}-\mathrm{N}$ is overestimated by $0.07 \AA$, leading to a deformation of the DPA ligand. As a consequence, the geometrical factors deduced from DFT are smaller by $10 \%$ than those deduced from X-rays structures for the closest ${ }^{1} \mathrm{H}$ while this discrepancy decreases for protons farther away. The position of the ethyl chain was found to be almost perpendicular to the pyridine ring of the DPA ligand from DFT geometry optimizations. To estimate the sensitivity of the ethyl chain position, the geometric parameters $G_{K}$ were calculated with a $10^{\circ}$ angle from this equilibrium position. A deviation of only $1 \%$ was found for the most distant proton of the $\mathrm{CH}_{3}$ groups $(\mathrm{H} 6)$. In light of the effect of the ligand positioning on the geometrical factors, the interpretation of experimental data as well as the $a b$ initio calculations were performed on X-rays structures. For $\left[\mathrm{An}^{\mathrm{VI}} \mathrm{O}_{2}(\mathrm{Et}-\mathrm{DPA})_{2}\right]^{2-}$ complexes, the ethyl chain was placed strictly perpendicular to the pyridine ring to avoid any bias in the interpretation due to its position. 
Table 1: Bond distances $(\AA)$, angles $\left(^{\circ}\right)$ and protons geometric parameters $G_{K}\left(10^{-3} \AA^{-3}\right)$ in the DFT optimized structure of $\left[U^{V I} O_{2}\left((E t-D P A)_{2}\right]^{2-}\right.$ and the X-rays structure $\mathrm{Li}_{2} \mathrm{An}^{V I} \mathrm{O}_{2}(\mathrm{DPA})_{2} \cdot 2 \mathrm{H}_{2} \mathrm{O}$. ${ }^{[30]}$ Protons are labelled according to Figure 1 and are averaged on chemically equivalent positions.

\begin{tabular}{|c|c|c|c|c|c|c|c|c|}
\hline & $A n=0$ & $A n-0$ & $A n-N$ & $\mathrm{O}-\mathrm{An}-\mathrm{N}$ & $G_{H 3}$ & $G_{H 4}$ & $G_{H 5}$ & $G_{H 6}$ \\
\hline$\left[\mathrm{U}^{\mathrm{VI}} \mathrm{O}_{2}\left((\mathrm{Et}-\mathrm{DPA})_{2}\right]^{2-a}\right.$ & 1.81 & 2.46 & 2.72 & 92 & -5.29 & -3.41 & -2.39 & -1.60 \\
\hline $\begin{array}{c}\mathrm{Li}_{2} \mathrm{U}^{\mathrm{VI}} \mathrm{O}_{2}(\mathrm{DPA})_{2} \cdot 2 \mathrm{H}_{2} \mathrm{O}^{b} \\
{\left[\mathrm{U}^{\mathrm{VI}} \mathrm{O}_{2}(\mathrm{Et}-\mathrm{DPA})_{2}\right]^{2-c}}\end{array}$ & $1.777(2)$ & $2.453(2)$ & $2.654(2)$ & $90.1(1)$ & -5.77 & & -2.41 & -1.68 \\
\hline $\begin{array}{l}\mathrm{Li}_{2} \mathrm{~Np}^{\mathrm{VI}} \mathrm{O}_{2}(\mathrm{DPA})_{2} \cdot 2 \mathrm{H}_{2} \mathrm{O}^{b} \\
{\left[\mathrm{~Np}^{\mathrm{VI}} \mathrm{O}_{2}(\mathrm{Et}-\mathrm{DPA})_{2}\right]^{2-c}}\end{array}$ & $1.759(1)$ & $2.45(1)$ & $2.648(1)$ & $90.8(1)$ & -5.79 & -3.61 & -2.44 & -1.69 \\
\hline $\begin{array}{c}\mathrm{Li}_{2} \mathrm{Pu}^{\mathrm{VI}} \mathrm{O}_{2}(\mathrm{DPA})_{2} \cdot 2 \mathrm{H}_{2} \mathrm{O}^{b} \\
{\left[\mathrm{Pu}^{b I} \mathrm{O}_{2}(\mathrm{Et}-\mathrm{DPA})_{2}\right]^{2-c}}\end{array}$ & $1.747(3)$ & $2.47(2)$ & $2.642(3)$ & $93.0(1)$ & -5.82 & -3.63 & -2.45 & -1.70 \\
\hline
\end{tabular}

a: this work. DFT optimized geometry. $b$ : from reference ${ }^{[30]}$. $c$ : structure built from X-rays with the ethyl chain perpendicular to the pyridine ring

Magnetic susceptibility tensor from experiment. The studied complexes are not strictly axial, but the presence of the two DPA ligands in the equatorial plane creates a structure sensibly equivalent to a C6 axis. The ab initio calculations confirm that the $X$ tensor is axial along the $y l$ bond and the equatorial values almost degenerate $\left(\chi_{x x}=\chi_{y y}\right)$. Consequently, we assume in the following that the magnetic susceptibility tensor $\chi$ reduces to the axial and equatorial values, $\chi_{\|}$and $\chi_{\perp}$. The isotropic average and the anisotropy are then expressed as $\chi_{m}=\frac{1}{3}\left(\chi_{\|}+2 \chi_{\perp}\right)$ and $\Delta \chi_{a x}=\chi_{\|}-\chi_{\perp}$, respectively. Accordingly, the knowledge of $\chi_{m}$ and $\Delta \chi_{a x}$ allows to estimate $\chi_{\|}$and $\chi_{\perp}$.

SQUID and Evans method. The temperature dependence of the molar magnetic susceptibility, $\chi_{m}^{S Q U I D}$, for the $\mathrm{Li}_{2} \mathrm{~Np}^{\mathrm{VI}} \mathrm{O}_{2}$ (DPA) $)_{2} \cdot 2 \mathrm{H}_{2} \mathrm{O}$ solid compound between 2 and $300 \mathrm{~K}$ is depicted as $\chi_{m}^{S Q U I D} T=f(T)$ in Figure 2 .

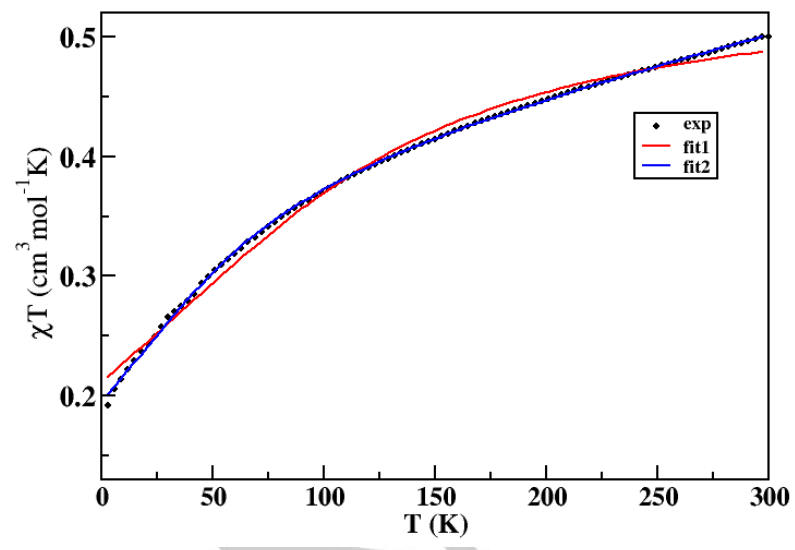

Figure 2: Molar magnetic susceptibility as a function of temperature with a field of $1 \mathrm{~T}$ for the $\mathrm{Li}_{2} \mathrm{~Np}^{\mathrm{VI}} \mathrm{O}_{2}$ (DPA) $)_{2} \cdot 2 \mathrm{H}_{2} \mathrm{O}$ compound. The red and blue lines show the fits using Eq. 21 without and with TIP respectively.
The value of $0.50 \mathrm{~cm}^{3} \mathrm{~K} \mathrm{~mol}^{-1}$ at $300 \mathrm{~K}$ is below the value of an isolated ion within the LS coupling scheme $\left(0.80 \mathrm{~cm}^{3} \mathrm{~K} \mathrm{~mol}^{-1}\right.$ for $\mathrm{Np}^{\mathrm{VI}}$ with a ${ }^{2} \mathrm{~F}_{5 / 2}, g_{5 / 2}=6 / 7$ ground state). When the temperature decreases, $\chi_{m}^{\text {SQUID }} T$ continuously diminishes reaching $0.19 \mathrm{~cm}^{3}$ $\mathrm{K} \mathrm{mol}^{-1}$ at $3 \mathrm{~K}$. The SQUID value for the isotropic average magnetic susceptibility $\chi_{m}^{\text {SQUID }}=(2.1 \pm 0.2) \cdot 10^{-8} \mathrm{~m}^{3} \mathrm{~mol}^{-1}$ at 298 $\mathrm{K}$, can be compared to value evaluated by NMR in $\left[\mathrm{D}_{7}\right] \mathrm{DMF}$ solution from Evans method, ${ }^{[44]} \chi_{m}^{\text {Evans }}=(1.8 \pm 0.2) \cdot 10^{-8} \mathrm{~m}^{3} \mathrm{~mol}^{-}$ ${ }^{1}$ at $298 \mathrm{~K}$. Those values are comparable, but the latter is slightly lower than the former. The techniques are different, but on the other hand, there are structural differences. In the crystalline structure, the anionic charge of the $\left[\mathrm{Np}^{\mathrm{VI}} \mathrm{O}_{2}(\mathrm{DPA})_{2}\right]^{2-}$ unit is compensated by $\mathrm{Li}^{+}$cations in two different crystallographic positions (see Figure SI-2), either in between two coordinating oxygen atoms of the DPA ligand, or linked to the uncoordinated oxygen atoms. The $\mathrm{Li}^{+}$cations are linked to one or two adjacent $\left.\mathrm{Li}_{2}\left[\mathrm{~Np}^{\mathrm{VI}} \mathrm{O}_{2} \text { (DPA) }\right)_{2}\right]$ entities forming an infinite chain. We showed that the cations in the $2^{\text {nd }}$ position do not impact the electronic properties of the paramagnetic center, to the contrary to the $\mathrm{Li}^{+}$ bonded to the coordinated oxygen atoms, as will be shown further. In the following, the solid $\mathrm{Li}_{2} \mathrm{~Np}^{\mathrm{VI}} \mathrm{O}_{2}$ (DPA) $)_{2} \cdot 2 \mathrm{H}_{2} \mathrm{O}$ will be described by the $\left[\mathrm{Np}^{\mathrm{VI}} \mathrm{O}_{2}(\mathrm{DPA})_{2}\right] \mathrm{Li}_{2}$ represented in Figure SI-2. The Mulliken charges of the $\left[\mathrm{Np}^{\mathrm{VI}} \mathrm{O}_{2}(\mathrm{DPA})_{2}\right]^{2-}$ complex with and without the two $\mathrm{Li}^{+}$cations are given in Table SI-2: it appears that the effect is a polarization of electron density of the DPA ligand in the presence of the positive charge which attracts the electron density towards the oxygen atoms ( 0.07 electron). Then, an important charge transfer from the DPA to the $\mathrm{Li}^{+}$cation reduces its charge to 0.48 . This finally decreases the Mulliken charge by 0.12 electron on the oxygen atoms directly bonded to the Np ion, and this affects the electronic properties by lowering the ligand field effect. Parker et al. have evidenced the sensitivity of the magnetic susceptibility anisotropy to the solvent in lanthanide complexes. ${ }^{[45-47]}$ The solvent molecules induces geometrical variations and transforms $\Delta \chi_{a x}$ from prolate to oblate, while in the present case, solvent molecules impact the magnetic properties through an electronic interaction with the paramagnetic center. 

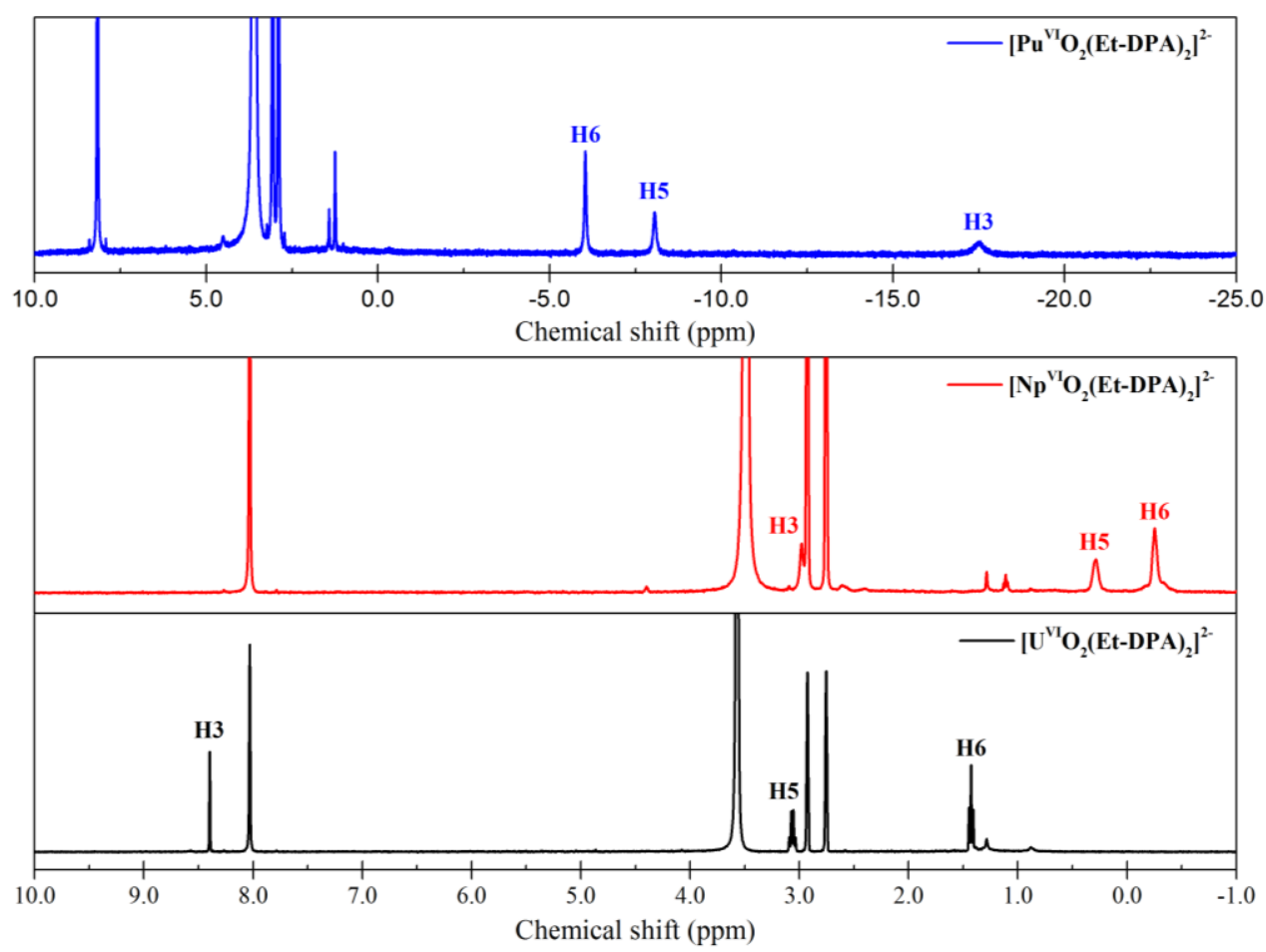

Figure 3: ${ }^{1} \mathrm{H}$ NMR spectra of $\left[\mathrm{An}^{\mathrm{VI}} \mathrm{O}_{2}(\mathrm{Et}-\mathrm{DPA})_{2}\right]^{2-}$ complexes at $298 \mathrm{~K}$ in $\left[\mathrm{D}_{7}\right] \mathrm{DMF}$ at $9.4 \mathrm{~T}$.

${ }^{1} \mathrm{H}$ paramagnetic chemical shifts. ${ }^{1} \mathrm{H}$ NMR spectra of $\left[\mathrm{An}^{\mathrm{VI}} \mathrm{O}_{2}(\mathrm{DPA})_{2}\right]^{2-}$ and $\left[\mathrm{An}^{\mathrm{VI}} \mathrm{O}_{2}(\mathrm{Et}-\mathrm{DPA})_{2}\right]^{2-}$ complexes were recorded in $\left[D_{7}\right] D M F$ at $298 \mathrm{~K}$ at $9.4 \mathrm{~T}$. Figure 3 shows the ${ }^{1} \mathrm{H}$ spectra of $\left[\mathrm{An}^{\mathrm{VI}} \mathrm{O}_{2}(\mathrm{Et}-\mathrm{DPA})_{2}\right]^{2-}$ complexes as example. The paramagnetic induced shifts $\delta_{K}^{p}$ were deduced by using the uranium complexes, $\left[\mathrm{U}^{\mathrm{VI}} \mathrm{O}_{2}(\mathrm{DPA})_{2}\right]^{2-}$ and $\left[\mathrm{U}^{\mathrm{VI}} \mathrm{O}_{2}(\mathrm{Et}-\mathrm{DPA})_{2}\right]^{2-}$ as diamagnetic references. The chemical shifts and pNMR chemical shifts obtained at room temperature $(298 \mathrm{~K})$ are reported in Table 2.

Table 2: ${ }^{1} \mathrm{H}$ chemical and pNMR chemical shifts (ppm) in $\left[\mathrm{D}_{7}\right] \mathrm{DMF}$ at $9.4 \mathrm{~T}$ and $298 \mathrm{~K}$ in $\left[\mathrm{An}^{\mathrm{VI}} \mathrm{O}_{2}(\mathrm{DPA})_{2}\right]^{2-}$ and $\left[\mathrm{An}^{\mathrm{VI}} \mathrm{O}_{2}(\mathrm{Et}-\mathrm{DPA})_{2}\right]^{2-}$ complexes.

\begin{tabular}{|c|c|c|c|c|c|c|c|c|}
\hline & $\delta_{H 3}$ & $\delta_{H 3}^{p}$ & $\delta_{H 4}$ & $\delta_{H 4}^{p}$ & $\delta_{H 5}$ & $\delta_{H 5}^{p}$ & $\delta_{H 6}$ & $\delta_{H 6}^{p}$ \\
\hline \multicolumn{9}{|c|}{$\left[\mathrm{An}^{\mathrm{VI}} \mathrm{O}_{2}(\mathrm{DPA})_{2}\right]^{2-}$} \\
\hline $\mathrm{U}^{\mathrm{VI}}$ & 8.59 & 1 & 8.59 & 1 & 1 & 1 & 1 & 1 \\
\hline $\mathrm{Np}^{\mathrm{VI}}$ & 2.65 & -5.94 & 5.69 & -2.91 & I & / & / & I \\
\hline $\mathrm{Pu}^{\mathrm{VI}}$ & -17.72 & -26.31 & -5.67 & -14.26 & 1 & 1 & I & 1 \\
\hline \multicolumn{9}{|c|}{$\left[\mathrm{An}^{\mathrm{VI}} \mathrm{O}_{2}(\mathrm{Et}-\mathrm{DPA})_{2}\right]^{2-}$} \\
\hline $\mathrm{U}^{\mathrm{VI}}$ & 8.40 & I & & I & 3.06 & I & 1.43 & I \\
\hline $\mathrm{Np}^{\mathrm{VI}}$ & 2.89 & -5.51 & & I & 0.28 & -2.78 & -0.26 & -1.69 \\
\hline $\mathrm{Pu}^{\mathrm{VI}}$ & -17.62 & -26.02 & 1 & 1 & -8.02 & -11.27 & -6.18 & -7.61 \\
\hline
\end{tabular}

In the case of no Fermi contact contribution, the ratio $R_{K, K^{\prime}}$ between the AIS of two nuclei $K$ and $\mathrm{K}^{\prime}$ as expressed by Eq. 2 simplifies to the ratio of their geometrical parameters

$$
R_{K, K^{\prime}}=\frac{\delta_{K}^{p}}{\delta_{K^{\prime}}^{p}}=\frac{\delta_{K}^{p c}}{\delta_{K^{\prime}}^{p c}}=\frac{G_{K}}{G_{K^{\prime}}}
$$

In Table 3, the $R_{K, K}$, determined from the X-rays structures are compared to those deduced from the ${ }^{1} \mathrm{H}$ AIS at $298 \mathrm{~K}$ for the $\mathrm{Np}^{\mathrm{VI}}$ and $\mathrm{Pu} \mathrm{VI}^{\mathrm{I}}$ complexes. The good agreement between the geometrical and AIS ratios proves that ${ }^{1} \mathrm{H}$ AIS in those complexes are dominated by pseudocontact interactions. The spin densities determined from unrestricted DFT calculations (see Table SI-6) confirm this. The spin density tends to decrease with the distance to the paramagnetic center, except for $\mathrm{C} 4$, the largest lies on the yle oxygen atoms, due to the strong bonding scheme. It is negative on the coordinating atoms, and then the sign alternates, due to spin polarization, and vanishes on the protons and aliphatic carbons atoms, in accordance with the observed zero Fermi contact AIS for the protons. In the noncoordinating carbon atoms, the spin density resides mostly in the $\pi$ system, and consequently does not spread to the protons. 
In the case of a pure dipolar interaction, Eq. 2 holds and the axial anisotropy $\Delta \chi_{a x}$ can be obtained from ${ }^{1} \mathrm{H}$ AIS analysis. Thereby, $\Delta \chi_{a x}^{e x p}$ is determined from the slope of the $\delta_{K}^{p c}=f\left(G_{K}\right)$ curves (see Figure SI-4), which equals to $\frac{10^{6}}{12 \pi N_{A}} \Delta \chi_{a x} . \Delta \chi_{a x}^{\text {exp }}=(2.2 \pm$ $0.1) \cdot 10^{-8}$ and $(10.1 \pm 0.2) \cdot 10^{-8} \mathrm{~m}^{3} \mathrm{~mol}^{-1}$ at $298 \mathrm{~K}$ for the $\mathrm{Np}^{\mathrm{VI}}$ and $\mathrm{Pu}^{\mathrm{VI}}$ complexes, respectively. Ab initio calculations demonstrate that the ethyl group does not affect the electronic structure of the electronic structure of the paramagnetic center. This justifies the previous use of all the ${ }^{1} \mathrm{H}$ nuclei from both DPA and Et - DPA ligands to determine the $\Delta \chi_{a x}^{\text {exp }}$ values. For the $\left[\mathrm{An}^{\mathrm{VI}} \mathrm{O}_{2}(\mathrm{DPA})_{2}\right]^{2-}$ complexes in solution, the two components of the magnetic susceptibility tensor, $\chi_{\|}$and $\chi_{\perp}$, are deduced from the isotropic average and anisotropic values, $\chi_{\mathrm{m}}^{\text {Evans }}$ and $\Delta \chi_{a x}^{\text {exp }}$, and are given in Table 4.

Table 3: $\mathrm{R}_{\mathrm{KK}}$ of Eq. 4 determined from geometrical parameters deduced from $X$-rays structures and from ${ }^{1} \mathrm{H}$ pNMR chemical shifts in $\left[\mathrm{D}_{7}\right] \mathrm{DMF}$ at $9.4 \mathrm{~T}$ and $298 \mathrm{~K}$ in $\left[\mathrm{An}^{\mathrm{VI}} \mathrm{O}_{2}(\mathrm{DPA})_{2}\right]^{2-}$ and $\left[\mathrm{An}^{\mathrm{VI}} \mathrm{O}_{2}(\mathrm{Et}-\mathrm{DPA})_{2}\right]^{2-}$ complexes.

\begin{tabular}{lcccccc}
$\mathrm{An}^{\mathrm{VI}}$ & $\frac{G_{H 3}}{G_{H 4}}$ & $\frac{\delta_{H 3}^{p}}{\delta_{H 4}^{p}}$ & $\frac{G_{H 3}}{G_{H 6}}$ & $\frac{\delta_{H 3}^{p}}{\delta_{H 6}^{p}}$ & $\frac{G_{H 5}}{G_{H 6}}$ & $\frac{\delta_{H 5}^{p}}{\delta_{H 6}^{p}}$ \\
\hline $\mathrm{Np}^{\mathrm{VI}}$ & 1.6 & 2.0 & 3.4 & 3.2 & 1.4 & 1.7 \\
$\mathrm{Pu}^{\mathrm{VI}}$ & 1.6 & 1.9 & 3.4 & 3.4 & 1.4 & 1.5 \\
\hline
\end{tabular}

Electronic structure from ab initio calculations. The SQUID measurements are performed on the solid $\mathrm{Li}_{2} \mathrm{~Np}^{\mathrm{VI}} \mathrm{O}_{2}$ (DPA) $)_{2} \cdot 2 \mathrm{H}_{2} \mathrm{O}$ compound and $\mathrm{NMR}$ analysis on $\left[\mathrm{Np}^{\mathrm{VI}} \mathrm{O}_{2}(\mathrm{Et}-\mathrm{DPA})_{2}\right]^{2-}, \quad\left[\mathrm{Np}^{\mathrm{VI}} \mathrm{O}_{2}(\mathrm{DPA})_{2}\right]^{2-},\left[\mathrm{Pu}^{\mathrm{VI}} \mathrm{O}_{2}\right.$ $(\mathrm{Et}-\mathrm{DPA})]_{2}{ }^{2-}$ and $\left[\mathrm{Pu}^{\mathrm{VI}} \mathrm{O}_{2}(\mathrm{DPA})_{2}\right]^{2-}$ complexes in $\left[\mathrm{D}_{7}\right] \mathrm{DMF}$ solution. As previously discussed, the $\mathrm{Li}^{+}$cations linked to the non-coordinating oxygen atoms of the DPA ligands do not impact the electronic structure of the actinide center and the $\left.\left[\mathrm{Np}^{\mathrm{VI}} \mathrm{O}_{2} \text { (DPA) }\right)_{2}\right] \mathrm{Li}_{2}$ complex as represented in Figure SI-2 was considered. We showed as well that the ethyl group does not affect the electronic structure of the actinide and in the following, only the results for the $\left[\mathrm{An}^{\mathrm{VI}} \mathrm{O}_{2}(\mathrm{DPA})_{2}\right]^{2-}$ complex are discussed. The $\mathrm{X}$-rays structures were considered for the calculations.

The SO-CASPT2 method has already been successfully applied to describe the excited states ${ }^{[48-49]}$ and magnetic properties ${ }^{[50]}$ of $\left[\mathrm{An}^{\mathrm{VI}} \mathrm{O}_{2}\right]^{2+}$ complexes. The ${ }^{13} \mathrm{C}$ pNMR chemical shifts in carbonate actinide complexes were described by Autschbach's group..$^{[9,27]}$ The actinyl cation is strongly correlated due to its two triple bonds, which means that electron correlation, charge transfer and spin polarization should be addressed and large active spaces are needed in order to reproduce correctly the magnetic properties.

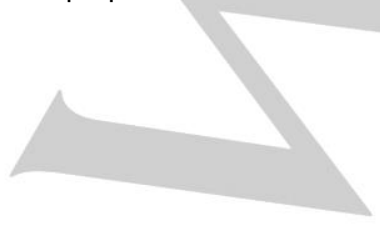

The six active orbitals of the CAS $(1,6)$ are shown on Figure 4.

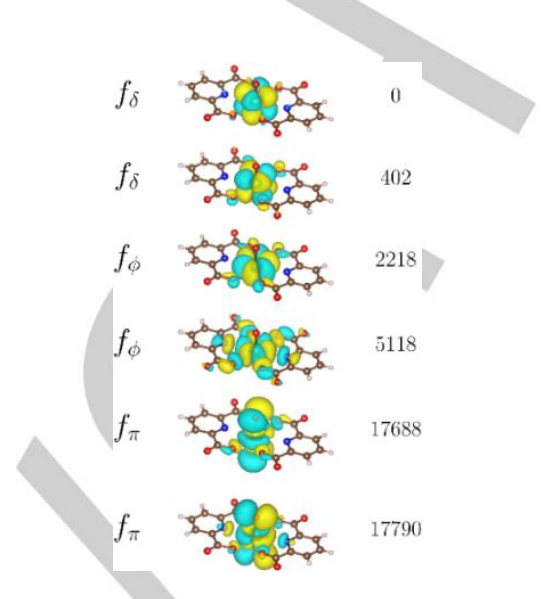

Figure 4: $5 f$ active orbitals of $\left[\mathrm{Np}^{\mathrm{VI}} \mathrm{O}_{2}(\mathrm{DPA})_{2}\right]^{2-}$. Numbers on the right side are the energies in $\mathrm{cm}^{-1}$. The isovalue is $0.08 \mathrm{e}^{-} / \mathrm{bohr}^{3}$.

The $5 f$ orbitals are antibonding with the ligands orbitals, the strongest the interaction is, the most destabilized the orbital is. The $f_{\sigma}$ orbital is the most destabilized and does not need to be considered as active. The $f_{\pi}$ orbitals interact with the oxo $p_{\pi}$ and are strongly destabilized at more than $17000 \mathrm{~cm}^{-1}$, with a small splitting due to a small $\sigma$ interaction with the DPA ligands. The $f_{\varphi}$ and $f_{\delta}$ orbitals are non-bonding with the axial oxo groups and act as a hotbed for the unpaired electrons. Spin density is mostly localized on the metal. Due to the trigonal symmetry of the equatorial ligands, the two $f_{\varphi}$ orbitals split by $3000 \mathrm{~cm}^{-1}$; the destabilized one overlaps with the $\sigma$ donating orbitals of the 6 coordinating nitrogen and oxygen atoms of the DPA, while the other one denotes a $\pi$ overlap. The two $f_{\delta}$ orbitals do not have any $\sigma$ bonding with the orbitals of the equatorial ligands due to their equatorial nodal plane; one of them denotes a small $\pi$ overlap and is destabilized by $400 \mathrm{~cm}^{-1}$. As shown in reference [50], the splitting between the $f_{\varphi}$ and $f_{\delta}$ orbitals determine the nature of the ground KD and the magnetic properties of the complex. In the actinyl ion, the $f_{\delta}$ orbitals span $e_{3 / 2}$ and $e_{5 / 2}$ spinors and the $f_{\varphi}$ orbitals span $e_{5 / 2}$ and $e_{7 / 2}$ spinors. In the present case, the $e_{5 / 2}$ spinor which arises from the mixing of $f_{\delta}$ and $f_{\varphi}$ orbitals is the ground one. Consequently, the $f_{\delta}-f_{\varphi}$ energy gap determines the composition of the state and plays a key role. The active space for RASSCF calculations is augmented by the $\sigma$ and $\pi$ orbitals of the oxo groups. This allows a better description of the charge fluctuation in the $\left[\mathrm{An}^{\mathrm{VI}} \mathrm{O}_{2}\right]^{2+}$ cation, as well as the spin polarization. This is evidenced by the Mulliken spin densities of +1.05 on $\mathrm{Np}$ and -0.03 on each 0 in the $\mathrm{Np}^{\mathrm{VI}}$ complex and +2.1 on $\mathrm{Pu}$ and 0.06 on each $\mathrm{O}$ in the $\mathrm{Pu}^{\mathrm{VI}}$ complex. 
Table 4: Principal components of the magnetic susceptibility tensor $\chi$ (in $10^{-8} \mathrm{~m}^{3} \mathrm{~mol}^{-1}$ ) at $298 \mathrm{~K}$ from experiment and ab initio calculations. The Curie contributions are evaluated from the ground doublet. $\chi_{\mathrm{m}}$ and $\Delta \chi_{\mathrm{ax}}$ are the isotropic average and axial anisotropic susceptibilities, respectively.

\begin{tabular}{|c|c|c|c|c|c|c|c|c|c|c|}
\hline Method & $\chi_{x x}^{\text {Curie }}$ & $\chi_{y y}^{\text {Curie }}$ & $\chi_{z Z}^{\text {Curie }}$ & $\Delta \chi_{a x}^{\text {Curie }}$ & $\chi_{m}^{\text {Curie }}$ & $\chi_{x x}$ & $\chi_{y y}$ & $\chi_{z z}$ & $\Delta \chi_{a x}$ & $\chi_{m}$ \\
\hline \multicolumn{11}{|c|}{$\left[\mathrm{Np}^{\mathrm{VI}} \mathrm{O}_{2}(\mathrm{DPA})_{2}\right]^{2-}$} \\
\hline Exp. & 1 & 1 & 1 & 1 & & $1.1 \pm 0.2$ & $1.1 \pm 0.2$ & $3.3 \pm 0.2$ & $2.2 \pm 0.1^{a}$ & $1.8 \pm 0.2^{b}$ \\
\hline SO-CASSCF & 0.05 & 0.04 & 1.33 & 1.29 & 0.47 & 0.47 & 0.48 & 1.67 & 1.20 & 0.87 \\
\hline SO-CASPT2 & 0.1 & 0.11 & 0.96 & 0.86 & 0.39 & 0.54 & 0.56 & 1.77 & 1.22 & 0.96 \\
\hline SO-CASPT2* & 0.27 & 0.27 & 0.41 & 0.14 & 0.32 & 0.61 & 0.72 & 2.14 & 1.47 & 1.16 \\
\hline SO-RASSCF & 0.17 & 0.16 & 0.91 & 0.75 & 0.41 & 0.70 & 0.74 & 2.18 & 1.46 & 1.21 \\
\hline SO-RASPT2 & 0.39 & 0.39 & 0.35 & -0.04 & 0.38 & 0.78 & 0.84 & 2.36 & 1.55 & 1.33 \\
\hline SO-RASPT2* & 0.74 & 0.84 & 0.32 & -0.47 & 0.63 & 0.86 & 0.96 & 3.29 & 2.38 & 1.70 \\
\hline SO-ZORA/PBE0 & 0.04 & 0.06 & 1.44 & 1.39 & 0.51 & & & & & \\
\hline \multicolumn{11}{|c|}{$\left[\mathrm{Np}^{\mathrm{VI}} \mathrm{O}_{2}(\mathrm{DPA})_{2}\right] \mathrm{Li}_{2}$} \\
\hline Exp. & & & & & & & & & & $2.1 \pm 0.2^{c}$ \\
\hline SO-CASSCF & 0.12 & 0.08 & 1.39 & 1.29 & 0.54 & 0.63 & 0.61 & 2.13 & 1.51 & 1.13 \\
\hline SO-CASPT2 & 0.28 & 0.21 & 1.07 & 0.83 & 0.52 & 0.71 & 0.66 & 2.53 & 1.84 & 1.31 \\
\hline SO-CASPT2* & 0.63 & 0.44 & 1.68 & 1.14 & 0.91 & 0.80 & 0.73 & 3.65 & 2.88 & 1.74 \\
\hline SO-RASSCF & 0.64 & 0.38 & 1.56 & 1.05 & 0.86 & 0.90 & 0.84 & 3.61 & 2.74 & 1.79 \\
\hline SO-RASPT2 & 0.79 & 0.66 & 1.23 & 0.51 & 0.90 & 0.92 & 0.86 & 3.77 & 2.88 & 1.86 \\
\hline SO-RASPT2* & 0.46 & 0.30 & 4.18 & 3.80 & 1.66 & 0.84 & 0.76 & 4.89 & 4.09 & 2.18 \\
\hline \multicolumn{11}{|c|}{$\left[\mathrm{Pu}^{\mathrm{VI}} \mathrm{O}_{2}(\mathrm{DPA})_{2}\right]^{2-}$} \\
\hline Exp. & & & & & $A$ & $0.7 \pm 0.1$ & $0.7 \pm 0.1$ & $10.8 \pm 0.2$ & $10.1 \pm 0.2^{a}$ & $4.1 \pm 0.1^{b}$ \\
\hline SO-CASSCF & 0.00 & 0.00 & 13.70 & 13.70 & 4.60 & 0.00 & 0.00 & 13.70 & 13.70 & 4.72 \\
\hline SO-CASPT2 & 0.00 & 0.00 & 12.76 & 12.76 & 4.29 & 0.17 & 0.17 & 12.80 & 12.63 & 4.42 \\
\hline SO-CASPT2* & 0.00 & 0.00 & 12.73 & 12.73 & 4.28 & 0.14 & 0.14 & 12.80 & 12.66 & 4.40 \\
\hline SO-RASSCF & 0.00 & 0.00 & 13.70 & 13.70 & 4.61 & 0.14 & 0.14 & 13.80 & 13.66 & 4.73 \\
\hline SO-RASPT2 & 0.00 & 0.00 & 13.52 & 13.52 & 4.54 & 0.17 & 0.17 & 13.50 & 13.33 & 4.66 \\
\hline SO-RASPT2* & 0.00 & 0.00 & 13.32 & 13.32 & 4.48 & 0.13 & 0.13 & 13.30 & 13.17 & 4.59 \\
\hline
\end{tabular}

${ }^{*}: 5 \mathrm{~d}$ and $5 \mathrm{p}$ orbitals are correlated ; a: deduced from the $\delta_{K}^{p c}=f\left(G_{K}\right)$ plots (See Figure SI-3) ; b: deduced from chemical shifts according to Evans method; $\mathrm{c}$ from SQUID.

In Table 5, $g$ factors are given along with the composition of the SF wave functions for the ground and excited Kramers doublet (KD1 and KD2) and their energy gap $\Delta E$, obtained with the different methods of calculation for $\left[\mathrm{Np}^{\mathrm{VI}} \mathrm{O}_{2}(\mathrm{DPA})_{2}\right]^{2-}$ and $\left[\mathrm{Np}^{\mathrm{VI}} \mathrm{O}_{2}(\mathrm{DPA})_{2}\right] \mathrm{Li}_{2}$. More results are provided by Tables SI-3 and $\mathrm{SI}-4$. For $\left[\mathrm{Np}^{\mathrm{VI}} \mathrm{O}_{2}(\mathrm{DPA})_{2}\right]^{2-}$, ground state anisotropies calculated with SO-CASSCF and SO-RASSCF methods are notably axial $\left(g_{\|} \gg g_{\perp} ; g_{\|}=g_{z z}\right.$ and $\left.g_{\perp}=g_{x x}, g_{y y}\right)$ whereas including successive dynamic correlation with SO-CASPT2 to SO-RASPT2 methods, the anisotropy almost becomes spherical $\left(g_{\|} \approx g_{\perp}\right)$ to planar $\left(g_{\|} \ll g_{\perp}\right)$. Two levels of frozen orbitals have been compared, freezing or not the $5 \mathrm{p}$ and the $5 \mathrm{~d}$ orbitals of the $\mathrm{Np}$ atom, the former scheme being the default option in MOLCAS. The effect of the $5 p$ and $5 d$ is in this case essential and emphasizes the effect of the correlation. The values of the $g$ factors arise from the composition of the KDs in terms of the SF states. The characteristic notations for the SF states $\Delta, \Phi, \Pi$ used here are indicating their parental states in the axial symmetry. $\Delta, \Phi$ and $\Pi$ correspond to the SF wave functions where the unpaired electron is in the $f_{\delta}, f_{\phi}$ and $f_{\pi}$ orbital respectively. And the composition can be explained from the SF energy levels in Table SI-3. Since SO coupling is introduced as a state interaction, the closer the states are in energy, the more they interact. The dynamic correlation correction on the SF$\mathrm{C}(\mathrm{R})$ ASSCF energies reduces the energy gap between the $\Delta$ and $\Phi$ states and results in a larger mixing at the SO level. The decomposition of the SO eigenvectors of KD1 shows an increased mixing of $\Phi$ states due to successive decrease of the energy gap $\Delta\left(E_{1} \& E_{2}\right)$ and $\Phi\left(E_{3} \& E_{4}\right)$ states going from CASSCF to RASPT2 level (from $2218 \mathrm{~cm}^{-1}$ to $1013 \mathrm{~cm}^{-1}$ in Table SI-3). For the $\left[\mathrm{Np}^{\mathrm{VI}} \mathrm{O}_{2}(\mathrm{DPA})_{2}\right]^{2-}$ complex, restricted 2-component DFT using the PBE0 functional was performed. The composition of the single occupied spinor in terms of $f_{\delta}$ and $f_{\phi}$ is similar to the SO-CASSCF function, leading to values of $g$ factors similar to this level of calculation.

The main effect of the two $\mathrm{Li}^{+}$counterions in $\left[\mathrm{Np}^{\mathrm{VI}} \mathrm{O}_{2}(\mathrm{DPA})_{2}\right] \mathrm{Li}_{2}$ is the stabilization of the two $\Phi\left(E_{3} \& E_{4}\right)$ states by $500 \mathrm{~cm}^{-1}$. KD1 
are therefore a larger weight on this component. With RASPT2, $E_{3}$ is divided by two (1013 vs $564 \mathrm{~cm}^{-1}$ ) by the presence of the $\mathrm{Li}^{+}$cations and $\Phi$ SF states becomes dominant in KD1, and this impacts dramatically the rhombicity of the $\mathbf{g}$ tensor. It shows that in this case, the counterions, since lying in the close vicinity of the coordination sphere, are by far not anecdotal.

Table 5: Energy $\left(\Delta E\right.$ in $\left.\mathrm{cm}^{-1}\right)$, composition in terms of SF states, $\Delta, \Phi$ and $\Pi$ (in \%) and $g$ factors of the two first KDs for different levels of calculation. In the case of SO-ZORA/PBE0, composition of the singly occupied spinor in terms of the orbitals.

\begin{tabular}{|c|c|c|c|c|c|c|c|c|}
\hline Method & $\mathrm{KD}$ & $\Delta E$ & $\Delta$ & $\Phi$ & $\Pi$ & $g_{x x}$ & $g_{y y}$ & $g_{z z}$ \\
\hline \multicolumn{9}{|c|}{$\left[\mathrm{Np}^{\mathrm{VI}} \mathrm{O}_{2}(\mathrm{DPA})_{2}\right]^{2-}$} \\
\hline \multirow{2}{*}{ SO-CASSCF } & KD1 & 0 & 95 & 2 & 3 & 0.3 & 0.3 & 1.8 \\
\hline & KD2 & 820 & 30 & 70 & 0.2 & 0.5 & 0.3 & 4.0 \\
\hline \multirow{2}{*}{ SO-CASPT2 } & KD1 & 0 & 93 & 5 & 2 & 0.5 & 0.5 & 1.6 \\
\hline & KD2 & 624 & 31 & 68 & 0.3 & 0.7 & 0.5 & 3.6 \\
\hline \multirow{2}{*}{ SO-CASPT2* } & KD1 & 0 & 86 & 12 & 2 & 0.8 & 0.8 & 1.0 \\
\hline & KD2 & 454 & 36 & 64 & 0.5 & 1.0 & 0.8 & 3.0 \\
\hline \multirow{2}{*}{ SO-RASSCF } & KD1 & 0 & 92 & 6 & 2 & 0.6 & 0.6 & 1.5 \\
\hline & KD2 & 455 & 31 & 68 & 0.3 & 0.8 & 0.6 & 3.7 \\
\hline \multirow{2}{*}{ SO-RASPT2 } & KD1 & 0 & 85 & 13 & 2 & 1.0 & 1.0 & 0.9 \\
\hline & KD2 & 418 & 37 & 62 & 0.5 & 1.1 & 0.9 & 2.9 \\
\hline \multirow{2}{*}{ SO-RASPT2* } & KD1 & 0 & 62 & 37 & 1.4 & 1.4 & 1.4 & 0.9 \\
\hline & KD2 & 333 & 58 & 40 & 1.7 & 1.5 & 1.4 & 1.0 \\
\hline SO-ZORA / PBE0 & & & 94 & 1.3 & 4.3 & 0.3 & 0.4 & 1.9 \\
\hline \multicolumn{9}{|c|}{$\left[\mathrm{Np}^{\mathrm{VI}} \mathrm{O}_{2}(\mathrm{DPA})_{2}\right] \mathrm{Li}_{2}$} \\
\hline \multirow{2}{*}{ SO-CASSCF } & KD1 & 0 & 94 & 4 & 3 & 0.3 & 0.4 & 1.9 \\
\hline & KD2 & 522 & 29 & 71 & 0.2 & 0.3 & 0.5 & 3.6 \\
\hline \multirow{2}{*}{ SO-CASPT2 } & KD1 & 0 & 88 & 10 & 2 & 0.3 & 0.7 & 1.8 \\
\hline & KD2 & 396 & 34 & 66 & 0.4 & 0.6 & 0.8 & 3.3 \\
\hline \multirow{2}{*}{ SO-CASPT2* } & KD1 & 0 & 65 & 34 & 1 & 0.4 & 1.0 & 2.4 \\
\hline & KD2 & 282 & 55 & 44 & 1 & 0.3 & 1.1 & 2.4 \\
\hline \multirow{2}{*}{ SO-RASSCF } & KD1 & 0 & 75 & 24 & 2 & 0.1 & 0.9 & 2.4 \\
\hline & KD2 & 250 & 47 & 52 & 1 & 0.6 & 1.0 & 3.0 \\
\hline \multirow{2}{*}{ SO-RASPT2 } & KD1 & 0 & 56 & 42 & 0.2 & 0.9 & 1.3 & 2.1 \\
\hline & KD2 & 298 & 64 & 35 & 2 & 1.8 & 1.4 & 0.3 \\
\hline \multirow{2}{*}{ SO-RASPT2* } & KD1 & 0 & 33 & 67 & 0.3 & 1.1 & 0.8 & 3.3 \\
\hline & KD2 & 282 & 85 & 12 & 2 & 0.9 & 1.0 & 1.6 \\
\hline
\end{tabular}

* $: 5 d$ and $5 p$ orbitals are correlated

In the case of $\left[\mathrm{Pu}^{\mathrm{VI}} \mathrm{O}_{2}(\mathrm{DPA})_{2}\right]^{2-}$, the SF triplet ground state corresponds to a configuration $\Psi=\operatorname{core} f_{\delta}^{1} f_{\phi}^{1}$. The two lowest SO states show almost similar decomposition and are almost degenerate without correlation. When the $5 p$ and $5 d$ orbitals are correlated, a gap of $84 \mathrm{~cm}^{-1}$ is obtained (see Table 6). These two states can be modelled as a non-Kramers doublet (NKD) with an effective spin $\tilde{S}=1 / 2$. The ground NKD is energetically well separated from the first excited states by about $3000 \mathrm{~cm}^{-1}$ such that interaction with those states plays a negligible role in determining its magnetic properties. The $g$-value deduced from the ground NKD is insensitive to the method of calculation since the composition is constant (see Table 6) and are very close to the values of the free ion $\left(g_{\|}=6.095\right.$ and $g_{\perp}=0 ;[27]$ the $\mathbf{g}$ tensor is axial along the $y l$ bond, and the equatorial values are zero, as it has to be in a NKD.

Table 6: SO energies (in $\mathrm{cm}^{-1}$ ) and the only non-zero $g$-value of the ground $\mathrm{NKD}\left(\left(E_{1} \& E_{2}\right)\right.$ of the $\left[\mathrm{Pu}^{\mathrm{VI}} \mathrm{O}_{2}(\mathrm{DPA})_{2}\right]^{2-}$ complex.

\begin{tabular}{cccccc} 
Method & $E_{1}$ & $E_{2}$ & $E_{3}$ & $E_{4}$ & $g_{z z}$ \\
\hline SO-CASSCF & 0 & 1 & 3221 & 5377 & 5.89 \\
SO-CASPT2 & 0 & 61 & 2865 & 4044 & 5.70 \\
SO-CASPT2* & 0 & 98 & 2845 & 3524 & 5.73 \\
SO-RASSCF & 0 & 0.2 & 3462 & 5511 & 5.89 \\
SO-RASPT2 & 0 & 8 & 3433 & 5457 & 5.85 \\
SO-RASPT2* & 0 & 84 & 3341 & 5035 & 5.84 \\
\hline
\end{tabular}

${ }^{*}: 5 d$ and $5 p$ orbitals are correlated

Chemical shifts from $a b$ initio calculations. Soncini and van den Heuvel ${ }^{[42]}$ have derived the general expression for the calculation of the pNMR shielding tensor $\sigma_{K}^{p}$ for a proton $K$

$$
\begin{aligned}
\sigma_{K, i j}^{p} & =\frac{1}{Q_{0}} \sum_{n} e^{-\beta E_{n}}\left[\beta \sum_{v, v^{\prime}}\left\langle n v\left|\widehat{m}_{i}\right| n v^{\prime}\right\rangle\left\langle n v^{\prime}\left|\widehat{F}_{K, j}\right| n v\right\rangle\right. \\
& \left.+\sum_{m \neq n} \sum_{v, \mu} \frac{\left\langle n v\left|\widehat{m}_{i}\right| m \mu\right\rangle\left\langle m \mu\left|\hat{F}_{K, j}\right| n v\right\rangle+\text { c.c. }}{E_{m}-E_{n}}\right]
\end{aligned}
$$

where $Q_{0}=\sum_{n} e^{-\beta E_{n}}$ is the partition function of the system in the absence of the external field or the fields from nuclear spin magnetic moments; $i, j \in\{x, y, z\} ; n, m$ count the electronic states, and $\mu, v$ their degenerate components and c.c. the complex conjugate terms. $\widehat{m}_{i}$ is the electronic magnetic moment operator and $\widehat{F}_{K, i}$ is proportional to the hyperfine operator and $\beta=1 / k_{B} T, k_{B}$ the Boltzmann constant. In the case of a KD modeled by a pseudospin $\tilde{S}=1 / 2$ neglecting the interactions with the excited states, Eq. 6 reduces to its first term only. This so-called Curie term can be expressed from the EPR $\mathbf{g}$ and the hyperfine matrix $\mathbf{A}_{K}$ as

$$
\boldsymbol{\sigma}_{K}^{p}=-\frac{\mu_{B}}{g_{K} \mu_{N}} \frac{\tilde{S}(\tilde{S}+1)}{3 k_{B} T} \mathbf{g}^{T} \cdot \mathbf{A}_{K}
$$

where $\mu_{B}$ is the Bohr magneton, $\mu_{N}$ the nuclear magneton and $g_{K}$ the nuclear $g$-factor of $K$. The isotropic pNMR chemical shift $\delta_{K}^{p}$ at temperature $T$ is evaluated as 


$$
\delta_{K}^{p}=-\frac{10^{6}}{3} \operatorname{tr}\left(\boldsymbol{\sigma}_{K}^{p}\right)=-\frac{10^{6}}{3}\left(\sigma_{K, x x}^{p}+\sigma_{K, y y}^{p}+\sigma_{K, z z}^{p}\right)
$$

where $\delta_{K}^{p}$ is expressed in ppm.

As shown in the previous Sections, the Fermi contact contribution is negligible. Within the dipolar approximation, the hyperfine operator can be expressed in terms of the electronic magnetic operator according to

$$
\widehat{\boldsymbol{F}}_{K}=-\frac{\mu_{0}}{4 \pi} \widehat{\boldsymbol{m}} \cdot \boldsymbol{T}_{K}
$$

where $\mathbf{T}_{K}=r_{K}^{-5}\left(3 \boldsymbol{r}_{K} \cdot \boldsymbol{r}_{K}-\mathbf{U} r_{K}^{2}\right)$ with $\boldsymbol{U}$ the unit tensor. As developed in the SI, within an axial symmetry, the component of the shielding tensor may be written as

$$
\sigma_{K, i i}^{p}=-\frac{\mu_{0} \mu_{\mathrm{B}}^{2}}{4 \pi} \frac{\mathrm{T}_{\mathrm{K}, \mathrm{ii}}}{\mathrm{Q}_{0}} \sum_{\mathrm{n}} \mathrm{e}^{-\beta \mathrm{E}_{\mathrm{n}}}\left[\beta\left\|\mathbf{M}_{i, n n}\right\|^{2}+2 \sum_{m \neq n} \frac{\left\|\mathbf{M}_{i, n m}\right\|^{2}}{E_{m}-E_{n}}\right]
$$

where \| $\|$ denotes the norm of a matrix and $\mathbf{M}_{i, n m}$ is the block matrix of operator $\widehat{m}_{i}$, the $\mathrm{i}^{\text {th }}$ component of $\widehat{\boldsymbol{m}}$ between the $n$ and $m$ manifolds, in $\mu_{B}$ units. The isotropic pNMR chemical shift may be written as

$$
\delta_{K}^{p}=\frac{10^{6} \mu_{0} \mu_{B}^{2}}{12 \pi} \frac{G_{K}}{Q_{0}} \sum_{n} e^{-\beta E_{n}}\left[\beta \Delta M_{n n}^{2}+2 \sum_{m \neq n} \frac{\Delta M_{n m}^{2}}{E_{m}-E_{n}}\right]
$$

where $\Delta M_{n n}^{2}=\left\|\mathbf{M}_{z, n n}\right\|^{2}-\frac{1}{2}\left(\left\|\mathbf{m}_{x, n n}\right\|^{2}+\left\|\mathbf{M}_{y, n n}\right\|^{2}\right)$. The magnetic susceptibility tensor $\chi$ described by the generalized Van Vleck equation

$$
\begin{aligned}
& \chi_{i j}= N_{A} \mu_{0} \mu_{\mathrm{B}}^{2} \\
& \frac{1}{Q_{0}} \sum_{n} e^{-\beta E_{n}}\left[\beta \sum_{v, v^{\prime}}\left\langle n v\left|\widehat{m}_{i}\right| n v^{\prime}\right\rangle\left\langle n v^{\prime}\left|\widehat{m}_{j}\right| n v\right\rangle\right. \\
&\left.+\sum_{m \neq n} \sum_{v, \mu} \frac{\left\langle n v\left|\widehat{m}_{i}\right| m \mu\right\rangle\left\langle m \mu\left|\widehat{m}_{j}\right| n v\right\rangle+\text { c.c. }}{E_{m}-E_{n}}\right]
\end{aligned}
$$

takes a very similar form since in the case of a pure dipolar interaction, the two operators of Eq. 5 are expressed with the magnetic moment operator. The diagonal terms of this tensor may be written as

$$
\begin{gathered}
\chi_{i i}=N_{A} \mu_{0} \mu_{B}^{2} \frac{1}{Q_{0}} \sum_{n} e^{-\beta E_{n}}\left[\beta\left\|\mathbf{M}_{i, n n}\right\|^{2}\right. \\
\left.+2 \sum_{m \neq n} \frac{\left\|\mathbf{M}_{i, n m}\right\|^{2}}{E_{m}-E_{n}}\right]
\end{gathered}
$$

$$
\chi_{m}=\frac{1}{3}\left(\chi_{x x}+\chi_{y y}+\chi_{z z}\right)
$$

and according to Eq. 11,

$$
\chi_{m}=N_{A} \mu_{0} \mu_{B}^{2} \frac{1}{Q_{0}} \sum_{n} e^{-\beta E_{n}}\left[\beta M_{n n}^{2}+2 \sum_{m \neq n} \frac{M_{n m}^{2}}{E_{m}-E_{n}}\right]
$$

where $M_{n n}^{2}=\left\|\mathbf{M}_{x, n n}\right\|^{2}+\left\|\mathbf{M}_{y, n n}\right\|^{2}+\left\|\mathbf{M}_{z, n n}\right\|^{2}$. The axial anisotropy as defined in Eq. 3 is deduced from Eq. 11 as

$$
\Delta \chi_{a x}=N_{A} \mu_{0} \mu_{B}^{2} \frac{1}{Q_{0}} \sum_{n} e^{-\beta E_{n}}\left[\beta \Delta M_{n n}^{2}+2 \sum_{m \neq n} \frac{\Delta M_{n m}^{2}}{E_{m}-E_{n}}\right]
$$

Eqs. 9 and 12 are very similar but summing up the three components, due to the geometrical prefactor in the former, the pNMR chemical shifts are issued from the axial properties while the magnetic susceptibility from the average isotropic ones. It should be mentioned that by combining Eqs. 10 and 15, one retrieves Eq. 2 .

In the previous equations, the properties are expressed as a sum over states. In order to model them with as few parameters as possible, the sum can be restricted to the low-lying states. The effect of the states not included in the model space can be quantified from ab initio calculations by comparing the results with all states included and with only the states from the model space.

Model for one isolated $K D$. In a KD, in the principal axes frame (PAF) of the $\mathbf{g}$ tensor, $\left\|\mathbf{M}_{i, n n}\right\|^{2}=\frac{1}{2} g_{i, n}^{2}$ where $g_{i, n}$ is the $\mathbf{g}$ factor in direction $i=x, y, z$. In the case of an axial symmetry, Eq. 10 reduces to its first term

$$
\delta_{K}^{p}=\frac{10^{6} \mu_{0} \mu_{B}^{2}}{12 \pi} G_{K} \frac{\beta}{4}\left(g_{z}^{2}-g_{\perp}^{2}\right)
$$

which is equivalent to Bertini's equation with $\tilde{S}=1 / 2$

$$
\chi_{u u}=N_{A} \mu_{0} \mu_{B}^{2} g_{u u}^{2} \frac{\tilde{S}(\tilde{S}+1)}{3 k_{B} T}
$$

Model for two isolated KDs. In the case of the $\left[\mathrm{Np}^{\mathrm{VI}} \mathrm{O}_{2}(\mathrm{DPA})_{2}\right]^{2-}$ complex, there are two low lying KDs populated at room temperature. One supposes that the PAF of the tensors $\mathbf{g}_{1}$ and $\mathbf{g}_{2}$ of the two KDs are identical and one denotes the energy gap $\Delta$. Restricting the sum to these two KDs, Eq. 9 becomes

The average isotropic magnetic susceptibility is defined as 


$$
\begin{gathered}
\sigma_{K, i i}^{p}=-\frac{\mu_{0} \mu_{B}^{2}}{4 \pi} T_{K, i i}\left[\beta \frac{\left(e^{\beta \Delta / 2} g_{i, 1}^{2}+e^{-\beta \Delta / 2} g_{i, 2}^{2}\right)}{4\left(e^{\beta \Delta / 2}+e^{-\beta \Delta / 2}\right)}\right. \\
\left.+\frac{\left(e^{\beta \Delta / 2}-e^{-\beta \Delta / 2}\right) M_{i, 12}^{2}}{\Delta\left(e^{\beta \Delta / 2}+e^{-\beta \Delta / 2}\right)}\right]
\end{gathered}
$$

In the axial symmetry, $g_{x, n}=g_{y, n}=g_{\perp, n}(n=1,2)$ and $M_{x, 12}=$ $M_{y, 12}=M_{\perp, 12}$. The axial components are defined according to $\Delta g_{n}^{2}=g_{z, n}^{2}-g_{\perp, n}^{2}$ and $\Delta M_{12}^{2}=M_{z, 12}^{2}-M_{\perp, 12}^{2}$, and Eq. 10 takes the form

$$
\begin{gathered}
\delta_{K}^{p}=\frac{10^{6} \mu_{0} \mu_{B}^{2}}{12 \pi} G_{K}\left[\beta \frac{\left(e^{\beta \Delta / 2} \Delta g_{1}^{2}+e^{-\beta \Delta / 2} \Delta g_{2}^{2}\right)}{4\left(e^{\beta \Delta / 2}+e^{-\beta \Delta / 2}\right)}\right. \\
\left.+\frac{\left(e^{\beta \Delta / 2}-e^{-\beta \Delta / 2}\right) \Delta M_{12}^{2}}{\Delta\left(e^{\beta \Delta / 2}+e^{-\beta \Delta / 2}\right)}\right]
\end{gathered}
$$

Similarly, the isotropic magnetic susceptibility is obtained from Eq. 14

$$
\begin{gathered}
\chi_{m}=N_{A} \mu_{0} \mu_{B}^{2}\left[\beta \frac{\left(e^{\beta \Delta / 2} g_{1}^{2}+e^{-\beta \Delta / 2} g_{2}^{2}\right)}{4\left(e^{\beta \Delta / 2}+e^{-\beta \Delta / 2}\right)}\right. \\
\left.+\frac{\left(e^{\beta \Delta / 2}-e^{-\beta \Delta / 2}\right) M_{12}^{2}}{\Delta\left(e^{\beta \Delta / 2}+e^{-\beta \Delta / 2}\right)}\right]
\end{gathered}
$$

where $g_{n}^{2}=g_{x, n}^{2}+g_{y, n}^{2}+g_{z, n}^{2}$ and similarly, the anisotropic axial susceptibility writes

$$
\begin{gathered}
\Delta \chi_{a x}=N_{A} \mu_{0} \mu_{B}^{2}\left[\beta \frac{\left(e^{\beta \Delta / 2} \Delta g_{1}^{2}+e^{-\beta \Delta / 2} \Delta g_{2}^{2}\right)}{4\left(e^{\beta \Delta / 2}+e^{-\beta \Delta / 2}\right)}\right. \\
\left.+\frac{\left(e^{\beta \Delta / 2}-e^{-\beta \Delta / 2}\right) \Delta M_{12}^{2}}{\Delta\left(e^{\beta \Delta / 2}+e^{-\beta \Delta / 2}\right)}\right]
\end{gathered}
$$

Model for an isolated non-Kramers doublet. The $\left[\mathrm{Pu}^{\mathrm{VI}} \mathrm{O}_{2}(\mathrm{DPA})_{2}\right]^{2-}$ complex should be modelled as a NKD. A NKD is modeled by two non-degenerate states $|1\rangle$ and $|2\rangle$ with an energy gap $\Delta$ and a Zeeman coupling $M_{z, 12}=\frac{1}{2} g_{z}$ in $z$ direction. In the other directions, there is no Zeeman coupling, as long as the doublet is considered. Eq. 9 becomes

$$
\begin{gathered}
\sigma_{K, i i}^{p}=-\frac{\mu_{0} \mu_{B}^{2}}{4 \pi} T_{K, i i} 2 \frac{\left(e^{\beta \Delta / 2}-e^{-\beta \Delta / 2}\right)}{\Delta\left(e^{\beta \Delta / 2}+e^{-\beta \Delta / 2}\right)} M_{i, 12}^{2} \\
=-\delta_{i z} \frac{\mu_{0} \mu_{B}^{2}}{4 \pi} T_{K, i i} \frac{1}{2} \frac{e^{\beta \Delta / 2}-e^{-\beta \Delta / 2}}{\Delta\left(e^{\beta \Delta / 2}+e^{-\beta \Delta / 2}\right)} g_{z}^{2}
\end{gathered}
$$

where $\delta_{i z}$ denotes the Kronecker symbol. The isotropic pNMR chemical shift is deduced from Eq. 10

$$
\delta_{K}^{p}=\frac{10^{6} \mu_{0} \mu_{B}^{2}}{12 \pi} G_{K} \frac{e^{\beta \Delta / 2}-e^{-\beta \Delta / 2}}{2 \Delta\left(e^{\beta \Delta / 2}+e^{-\beta \Delta / 2}\right)} g_{z}^{2}
$$

This equation arises from the $2^{\text {nd }}$ term, the so called Van Vleck term, of Eq. 10 since none of the state is degenerate. When $\Delta$ vanishes, since $x^{-1} \tanh x \stackrel{x \rightarrow 0}{\longrightarrow} 1$, where tanh denotes the hyperbolic tangent, Eq. 23 becomes the usual Curie term for a doublet $=\frac{10^{6} \mu_{0} \mu_{B}^{2}}{12 \pi k_{B} T} \frac{1}{4} G_{K} g_{z}^{2}$.

For the sake of completeness, we provide the equations for an isolated triplet in the SI.

pNMR chemical shifts from ab initio calculations. For the CAS based methods, the ${ }^{1} \mathrm{H}$ AIS were deduced from Bertini equation (Eq. 2), using the values of $\Delta \chi_{a x}$ from the ab initio calculations. Soncini Van Vleck equations split into the contributions of degenerate and non-degenerate states. In the case of a non-Kramers ion without any symmetry, the states are all non-degenerate, leading to only the $2^{\text {nd }}$ term. But the energy gaps may be very small, and when they vanish, one retrieves the Curie term. For thermal energies much larger than the energy gaps, their impact is not noticeable. It shows that the partition within a Curie and a Van Vleck term depends on the considered temperature. In the following, the Curie term is defined as the contribution from thermally populated states, and the Van Vleck term as the contribution arising from the coupling with other states. For the $\mathrm{Pu}{ }^{\mathrm{VI}}$ complex, the Curie term arises from the ground doublet. For the $\mathrm{Np}^{\mathrm{VI}}$ complex, the $1^{\text {st }}$ excited state lies around $300 \mathrm{~cm}^{-1}$, and the Curie term is considered to be the contribution of only the ground KD. AIS are calculated from 2components DFT calculations according to Eq. 6. The isotropic term of the HFC tensor are given in Table SI-5. Results for the magnetic susceptibility are summarized in Table 4. For the $\left[\mathrm{Np}^{\mathrm{VI}} \mathrm{O}_{2}(\mathrm{DPA})_{2}\right]^{2-}$ and $\left[\mathrm{Np}^{\mathrm{VI}} \mathrm{O}_{2} \quad(\mathrm{DPA})_{2}\right] \mathrm{Li}_{2}$ complexes, $\chi$ is much larger than its Curie contribution $\chi^{\text {Curie }}$, showing the importance of the Van Vleck contribution. Excited states other than KD2 do not provide any leading contribution. KD2 is slightly populated at $298 \mathrm{~K}$ and the large contribution of KD2 is due to its strong magnetic interaction with KD1. Due to the reduced energy gap in SO-RASPT2, this interaction becomes larger. $\Delta \chi_{a x}^{\text {Curie }}$ decreases when more correlation is included, to become negative in the case of $\left[\mathrm{Np}^{\mathrm{VI}} \mathrm{O}_{2}(\mathrm{DPA})_{2}\right]^{2-}$, while $\Delta \chi_{a x}$ increases. The importance of the Van Vleck contribution was already pointed out in the $\left[\mathrm{Np}^{\mathrm{VI}} \mathrm{O}_{2}\left(\mathrm{CO}_{3}\right)_{3}\right]^{4-}$ complex by Autschbach et al. The SO-RASPT2 results with the $5 \mathrm{p}$ and $5 \mathrm{~d}$ orbitals correlated provides values of both $\chi_{m}$ and $\Delta \chi_{a x}$ close to the experimental ones. $\chi_{m}$ is found to be smaller in $\left[\mathrm{Np}^{\mathrm{VI}} \mathrm{O}_{2}(\mathrm{DPA})_{2}\right]^{2-}$ than in $\left.\left[\mathrm{Np}^{\mathrm{VI}} \mathrm{O}_{2} \text { (DPA }\right)_{2}\right] \mathrm{Li}_{2}, 1.70$ vs $2.18 \cdot 10^{-8}$ $\mathrm{m}^{3} \mathrm{~mol}^{-1}$, and this follows the trend of the experimental values $(1.8 \pm 0.2) \cdot 10^{-8} \mathrm{~m}^{3} \mathrm{~mol}^{-1}$ for the $\left[\mathrm{Np}^{\mathrm{VI}} \mathrm{O}_{2}(\mathrm{DPA})_{2}\right]^{2-}$ complex in solution deduced from chemical shifts with Evans method vs (2.1 $\pm 0.24) \cdot 10^{-8} \mathrm{~m}^{3} \mathrm{~mol}^{-1}$ for $\mathrm{Li}_{2} \mathrm{~Np}^{\mathrm{VI}} \mathrm{O}_{2}$ (DPA $)_{2} \cdot 2 \mathrm{H}_{2} \mathrm{O}$ measured with the SQUID. $\chi_{m}$ was evaluated with SO-ZORA using Eq. 17. 
Table 7: ${ }^{1} \mathrm{H}$ pNMR chemical shifts (in ppm) at $298 \mathrm{~K}$ deduced from Eq. $2 . \delta_{\mathrm{K}}^{\mathrm{p} \text {,Curie }}$ is the Curie contribution arising from the ground doublet.

\begin{tabular}{|c|c|c|c|c|c|c|c|c|}
\hline Method & $\delta_{H 3}^{p, \text { Curie }}$ & $\delta_{H 3}^{p}$ & $\delta_{H 4}^{p, \text { Curie }}$ & $\delta_{H 4}^{p}$ & $\delta_{H 5}^{p, \text { Curie }}$ & $\delta_{H 5}^{p}$ & $\delta_{H 6}^{p, \text { Curie }}$ & $\delta_{H 6}^{p}$ \\
\hline \multicolumn{9}{|c|}{$\left[\mathrm{Np}^{\mathrm{VI}} \mathrm{O}_{2}(\mathrm{DPA})_{2}\right]^{2-} /\left[\mathrm{Np}^{\mathrm{VI}} \mathrm{O}_{2}(\mathrm{Et}-\mathrm{DPA})_{2}\right]^{2-}$} \\
\hline Exp. & / & $-5.9 /-5.5$ & / & -2.9 & / & -2.8 & / & -1.7 \\
\hline SO-CASSCF & -3.3 & -3.0 & -2.1 & -1.9 & -1.4 & -1.3 & -1.0 & -0.9 \\
\hline SO-CASPT2 & -2.2 & -3.1 & -1.4 & -1.9 & -0.9 & -1.3 & -0.6 & -0.9 \\
\hline SO-CASPT2* & -0.3 & -3.8 & -0.2 & -2.4 & -0.1 & -1.6 & -0.1 & -1.1 \\
\hline SO-RASSCF & -1.9 & -3.7 & -1.2 & -2.3 & -0.8 & -1.6 & -0.5 & -1.1 \\
\hline SO-RASPT2 & 0.1 & -4.0 & 0.1 & -2.5 & 0.0 & -1.7 & 0.0 & -1.2 \\
\hline SO- RASPT2* & 1.2 & -6.1 & 0.8 & -3.8 & 0.5 & -2.5 & 0.4 & -1.8 \\
\hline SO-ZORA/PBE0 & -3.5 & 1 & -2.7 & / & -1.7 & 1 & -1.0 & I \\
\hline \multicolumn{9}{|c|}{$\left[\mathrm{Pu}^{\mathrm{VI}} \mathrm{O}_{2}(\mathrm{DPA})_{2}\right]^{2-} /\left[\mathrm{Pu}^{\mathrm{VI}} \mathrm{O}_{2}(\mathrm{Et}-\mathrm{DPA})_{2}\right]^{2-}$} \\
\hline Exp. & I & $-26.3 /-26.0$ & l & -14.3 & 1 & -11.3 & 1 & -7.6 \\
\hline SO-CASSCF & -35.2 & -35.2 & -21.9 & -21.9 & -14.8 & -14.8 & -10.3 & -10.3 \\
\hline SO-CASPT2 & -33.3 & -32.4 & -20.7 & -20.3 & -13.9 & -13.6 & -9.6 & -9.4 \\
\hline SO-CASPT2* & -33.3 & -32.5 & -20.7 & -21.6 & -14.0 & -13.7 & -9.7 & -9.6 \\
\hline SO-RASSCF & -35.2 & -35.0 & -21.9 & -21.8 & -14.8 & -14.7 & -10.3 & -10.2 \\
\hline SO-RASPT2 & -34.7 & -34.2 & -21.6 & -21.3 & -14.6 & -14.4 & -10.2 & -10.0 \\
\hline SO- RASPT2* & -34.6 & -33.7 & -21.6 & -21.0 & -14.6 & -14.2 & -10.2 & -9.9 \\
\hline
\end{tabular}

${ }^{*}: 5 d$ and $5 p$ orbitals are correlated

The results are similar to the Curie term of the SO-CASSCF level, since only KD1 is included in the calculation.

For the $\left[\mathrm{Pu}^{\mathrm{VI}} \mathrm{O}_{2}(\mathrm{DPA})_{2}\right]^{2-}$ complex, the results depend very little on the method. The values of $\chi_{m}$ and $\Delta \chi_{a x}, 4.49$ and $13.17 \cdot 10^{-8}$ $\mathrm{m}^{3} \mathrm{~mol}^{-1}$, with SO-RASPT2, respectively, are found to be slightly larger than the experimental values $(4.06 \pm 0.1)$ and $(10.1 \pm$ $0.2) \cdot 10^{-8} \mathrm{~m}^{3} \mathrm{~mol}^{-1}$. For all the studied complexes, $\Delta \chi_{a x}$ is positive and larger than $\chi_{m}$, denoting a prolate shape of the magnetic moment of the paramagnetic center.

Results for the AIS are summarized in Table 7. Those results follow the conclusions for the magnetic susceptibility. The Van Vleck contribution plays a key role for the $\mathrm{Np}^{\mathrm{VI}}$ complexes, for $\mathrm{H} 3$, $\mathrm{H} 5$ and $\mathrm{H} 6$, the SO-RASPT2 results are in very good agreement with the experimental values. For $\mathrm{H} 4$, they overestimate the experimental value. The HFC tensor calculated with SO-ZORA is a pure dipolar one since the calculations are performed within a restricted scheme, avoiding the spin polarization to be correctly described. As for the magnetic susceptibility, the results for the AIS are the same as the Curie contribution with SO-CASSCF.

Temperature dependence. In the case of $\mathrm{Ln}^{\mathrm{III}}$ complexes, one takes advantage of the temperature dependence of the pNMR chemical shifts to separate the Fermi contact and pseudocontact contributions, which, according to Bleaney's theory, ${ }^{[17-18,24]}$ behave as $T^{-1}$ and $T^{-2}$, respectively. The $\left[\mathrm{An}^{\mathrm{VI}} \mathrm{O}_{2}\right]^{2+}-\mathrm{DPA}$ complexes are good candidates to investigate the temperature dependence of the pseudocontact interaction since the contact contributions are negligible even for the protons the closest from the paramagnetic center. The temperature dependence of the AIS were investigated for $\mathrm{H} 3$ and $\mathrm{H} 4$ protons in the $\left[\mathrm{Np}^{\mathrm{VI}} \mathrm{O}_{2}(\mathrm{DPA})_{2}\right]^{2-}$ and $\left[\mathrm{Pu}^{\mathrm{VI}} \mathrm{O}_{2}(\mathrm{DPA})_{2}\right]^{2-}$ complexes and are depicted in Figures 5 and 6 , respectively.
The regression analysis of the $\delta_{K}^{p}=f(1 / T)$ with $T^{-1}$ and $T^{-2}$ terms (see Figure SI-5 and Table SI-7) evidences very large $T^{-1}$ terms, even largely prevailing for the $\mathrm{Pu}^{\mathrm{VI}}$ complex, whereas no contact contribution is expected. This confirms that Bleaney's method for the separation between contact and dipolar contributions is not valid for the considered complexes. In order to analyze why, the temperature dependence was analyzed according to Eq. 5 .

For the $\mathrm{Np}^{\mathrm{VI}}$ complexes, this is completed by the magnetic susceptibility $\mathrm{T}$ dependence. In order to reduce the number of model parameters, the case of an axial symmetry is considered and the sum over the states is reduced to the states playing the primordial role, two KDs for the $\mathrm{Np}^{\mathrm{VI}}$ complexes and a NKD for the $\mathrm{Pu}^{\mathrm{VI}}$ one.

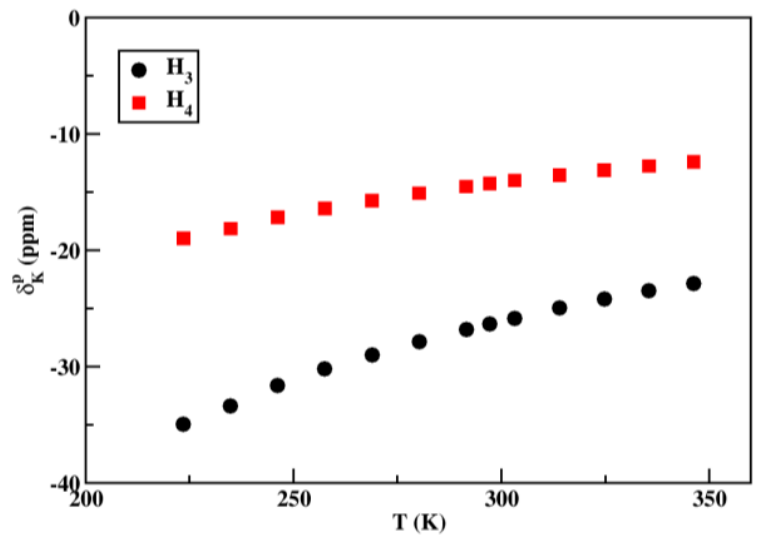

Figure 5: ${ }^{1} \mathrm{H}$ pNMR chemical shifts in $\left[\mathrm{D}_{7}\right] \mathrm{DMF}$ at $9.4 \mathrm{~T}$ as a function of temperature for the $\left[\mathrm{Np}^{\mathrm{VI}} \mathrm{O}_{2}(\mathrm{DPA})_{2}\right]^{2-}$ complex. 


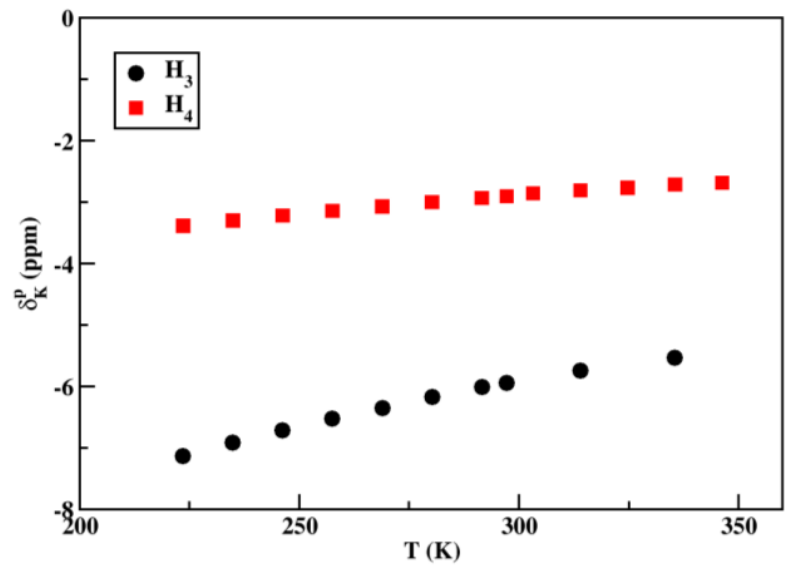

Figure 6: ${ }^{1} \mathrm{H}$ pNMR chemical shifts in $\left[\mathrm{D}_{7}\right] \mathrm{DMF}$ at $9.4 \mathrm{~T}$ as a function of temperature for the $\left[\mathrm{Pu}^{\mathrm{VI}} \mathrm{O}_{2}(\mathrm{DPA})_{2}\right]^{2-}$ complex.

$N p^{V I}$ complex. The $\chi_{m}^{\text {SQUID }} T=f(T)$ curve for the solid $\mathrm{Li}_{2} \mathrm{~Np}^{\mathrm{VI}} \mathrm{O}_{2}$ (DPA) $)_{2} \cdot 2 \mathrm{H}_{2} \mathrm{O}$ as shown on Figure 2 was fitted -using Eq. 20 in the temperature range $3-300 \mathrm{~K}$ according to four parameters: $\Delta$ the energy gap between the two KDs, $g_{1}^{2}$ and $g_{2}^{2}$ the isotropic magnetic moments of KD1 and KD2 and $M_{12}^{2}$ the isotropic coupling moment between KD1 and KD2. The optimized parameters are given in Table 8. A Temperature Independent Paramagnetic (TIP) term was added to Eq. 20 which improved the quality of the fitting procedure by taking into account the effect of the other excited states. This fitting procedure was benchmarked on the SO-RASPT2 curve of the $\left[\mathrm{Np}^{\mathrm{VI}} \mathrm{O}_{2}(\mathrm{DPA})_{2}\right] \mathrm{Li}_{2}$ complex. In this way, one can compare the fitted parameters to those directly calculated as ab initio energy levels and matrix elements. It appears that the energy gap $\Delta$ is underestimated by $15 \%$ and $23 \%$ without and with the TIP respectively. All fitted parameters match the ab initio ones within $20 \%, \Delta$ and $g_{2}^{2}$ being the less accurate. This confirms that the two-KDs model gather correctly the physical effects in the investigated temperature range. The discrepancies could arise from both the hypothesis of an axial symmetry, and mostly to the neglect of the interaction with the states out of the model space. The fitted parameters should be considered as effective ones. Surprisingly, the fit without TIP provides parameters closer to the $a b$ initio ones. We will therefore consider that the fits without the TIP contribution provides an energy gap closer to the 'real' one.

The fitting of the experimental SQUID $\chi_{m}^{\text {SQUID }} T=f(T)$ curve without any TIP contribution leads to a value of $\Delta=206 \mathrm{~cm}^{-1}$ which is smaller than the $a b$ initio ones. According to this fit, KD2 is more magnetic than KD1 $g_{2}^{2}>g_{1}^{2}(5.4$ vs 10.1) which is in good accordance with the SO-RASSCF values.

Table 8: Model parameters evaluated from ab initio calculations for the $\left[\mathrm{Np}^{\mathrm{VI}} \mathrm{O}_{2}(\mathrm{DPA})_{2}\right] \mathrm{Li}_{2}$ and the $\left[\mathrm{Np}^{\mathrm{VI}} \mathrm{O}_{2}(\mathrm{DPA})_{2}\right]^{2-}$ or deduced by fitting the $\chi_{\mathrm{m}}, \Delta \chi_{\mathrm{ax}}$ and $\delta_{\mathrm{K}}^{\mathrm{p}}$ curves, respectively. $\Delta$ in $\mathrm{cm}^{-1}$.

\begin{tabular}{|c|c|c|c|c|c|c|c|c|c|c|}
\hline & & $\Delta$ & $g_{1}^{2}$ & $\Delta g_{1}^{2}$ & $g_{2}^{2}$ & $\Delta g_{2}^{2}$ & $\Delta g_{1}^{2}-\Delta g_{2}^{2}$ & $\Delta g_{1}^{2}+\Delta g_{2}^{2}$ & $M_{12}^{2}$ & $\Delta M_{12}^{2}$ \\
\hline \multicolumn{11}{|c|}{$\left[\mathrm{Np}^{\mathrm{VI}} \mathrm{O}_{2}(\mathrm{DPA})_{2}\right] \mathrm{Li}_{2}$} \\
\hline SO-CASSCF & ab initio & 522 & 4.0 & 3.6 & 15.5 & 14.9 & -11.2 & 18.5 & 2.0 & 0.1 \\
\hline SO-CASPT2 & $a b$ initio & 396 & 3.9 & 3.1 & 12.1 & 10.6 & -7.5 & 13.8 & 2.6 & 1.2 \\
\hline SO-CASPT2* & ab initio & 282 & 6.8 & 5.1 & 6.6 & 5.2 & 0.0 & 10.3 & 3.2 & 2.7 \\
\hline SO-RASSCF & ab initio & 250 & 6.2 & 5.4 & 10.3 & 8.6 & -3.1 & 14.0 & 3. 0 & 2.1 \\
\hline SO-RASPT2 & ab initio & 298 & 6.7 & 3.0 & 5.2 & -2.4 & 5.4 & 0.6 & 4. 0 & 3.8 \\
\hline \multirow[t]{3}{*}{ SO-RASPT2* } & ab initio & 440 & 12.5 & 9.8 & 4.2 & 1.5 & 8.3 & 11.4 & 2.9 & 1.1 \\
\hline & fit $\chi_{m}{ }^{\S}$ & 372 & 10.0 & & 7.7 & & & & 2.2 & \\
\hline & fit $\chi_{m}$ with TIP§ & 338 & 10.0 & & 10.0 & & & & 2.2 & \\
\hline \multicolumn{11}{|c|}{$\left[\mathrm{Np}^{\mathrm{VI}} \mathrm{O}_{2}(\mathrm{DPA})_{2}\right]^{2-}$} \\
\hline SO-CASSCF & $a b$ initio & 820 & 3.5 & 3.2 & 16.3 & 15.8 & -12.6 & 19.1 & 0.6 & 0.0 \\
\hline SO-CASPT2 & $a b$ initio & 624 & 3.0 & 2.2 & 13.5 & 12. 4 & -10.3 & 14.6 & 0.8 & \\
\hline SO-CASPT2* & ab initio & 454 & 2.4 & 0.4 & 10.6 & 8.0 & -7.7 & 8.4 & 1.1 & 2. 1 \\
\hline SO-RASSCF & ab initio & 455 & 3.1 & 1.9 & 14.4 & 12.9 & -11.0 & 14.8 & 0.9 & 0.8 \\
\hline SO-RASPT2 & ab initio & 418 & 2.8 & -0.1 & 10.8 & 7.6 & -7.7 & 7.5 & 1.2 & \\
\hline \multirow[t]{3}{*}{ SO-RASPT2* } & ab initio & 333 & 4.9 & -1.1 & 5.2 & -1.2 & 0.1 & -2.3 & 1.5 & 4.5 \\
\hline & fit $\Delta \chi^{\#}$ & 360 & & -1.0 & & -3.0 & 2.0 & -4.0 & & 4.6 \\
\hline & fit $\Delta \chi$ polynom $\%$ & 260 & & & & & & -4.7 & & 6.1 \\
\hline \multicolumn{11}{|c|}{ Fit of the experimental curves } \\
\hline \multirow[t]{2}{*}{ SQUID } & fit $\chi_{m} T$ & 206 & 5.4 & & 10.1 & & & & 3.1 & \\
\hline & fit $\chi_{m} T$ with TIP & 113 & 5.0 & & 7.0 & & & & 1.8 & \\
\hline pNMR shift H3 & fit polynom $\%$ & 306 & & & & & & -6.7 & & 5.7 \\
\hline pNMR shift H4 & fit polynom \% & 306 & & & & & & -8.7 & & 5.4 \\
\hline
\end{tabular}

${ }^{*}: 5 \mathrm{~d}$ and 5 p orbitals are correlated. $\$$ : Eq. 19 , T range: $3-300 \mathrm{~K} . \#:$ Eq. 20 , T range: $250-350 \mathrm{~K} . \%:$ Eq. 23, T range: $250-350 \mathrm{~K}$. 
The fit of the AIS curves by Eq. 19 was not successful as data are only available on a short temperature window $(130 \mathrm{~K})$ and it needs four independent parameters: the anisotropic magnetic parameters $\Delta g_{1}^{2}, \Delta g_{2}^{2}, \Delta M_{12}^{2}$ and the energy gap $\Delta$. This leads to an over-parametrization, taking into account all the details of experimental uncertainties. The results are unstable according to the considered protons and to the number of considered points. We tried a polynomial fit, since it permits a smoothing of the curve. Since $\Delta$ is of some 100 of $\mathrm{cm}^{-1}$, one can consider the high The $T^{-1}$ term corresponds to the Curie contribution at high temperature, arising from the total magnetic moment of the two occupied KDs as shown in the SI. This term vanishes in lanthanide complexes because all the states issued from the ground $J$ manifold are statically populated at room temperature, since they are split by only some $100 \mathrm{~cm}^{-1}$. In this case, Eq. 9 runs over the whole $J$ manifold and the magnetic moment is isotropic $\mu_{B} g_{J}^{2} J(J+1)$ recovering the spherical symmetry of the free ion. The chemical shift sums over the three components of the pNMR shielding tensor and vanishes due the geometrical factors, $\sigma_{K, x x}^{p}+$ $\sigma_{K, y y}^{p}+\sigma_{K, z z}^{p}=\sum_{i=x, y, z} T_{K, i} \chi_{i i}=0$. The $T^{-1}$ term then vanishes. In the present case, the ground $J=5 / 2$ manifold splits in three KDs by more than $6000 \mathrm{~cm}^{-1}$. It follows that the magnetic moment at room temperature is temperature dependent. The $T^{-1}$ term does not vanish because not all the components of a given $J$ manifold are populated. It confirms that Bleaney's approach is not valid for the description of the actinyl complexes due to the larger splitting of the states of the free ion.

Since $\Delta$ corresponds to the thermal energy at room temperature, many $T^{-n}$ terms of the polynomial expansion of Eq. 24 are needed. $\Delta g_{1}^{2}$ and $\Delta g_{2}^{2}$ are found to be similar in the SO-RASPT2 calculation, we therefore supposed that $\Delta g_{1}^{2}-\Delta g_{2}^{2}$ was negligible, and consequently, neglected the $T^{-n}$ terms of even orders. The $\delta_{K}^{p}=f(1 / T)$ curve was fitted by a $A T^{-1}+C T^{-3}+E T^{-5}$ function. This permits to determine the values of $\Delta, \Delta M_{12}^{2}$ and $\Delta g_{1}^{2}+\Delta g_{2}^{2}$. They are given in Table 8 . As a benchmark, the $\Delta \chi_{a x}$ curve calculated with SO-RASPT2 for the $\left[\mathrm{Np}^{\mathrm{VI}} \mathrm{O}_{2}(\mathrm{DPA})_{2}\right]^{2-}$ complex was fitted in the $250-350 \mathrm{~K}$ range, both using Eq. 21 and its polynomial expansion. These parameters can be compared to those directly from the $a b$ initio calculations. The fitting with the full function overestimates the value of $\Delta$ by $10 \%$ while using the polynomial expansion, it underestimates it by $20 \%$. The magnetic parameters are well estimated by the former and slightly too large with the latter, the signs being correct in the two cases. The sign of $\Delta g_{1}^{2}+\Delta g_{2}^{2}$ gives information about the anisotropy of the magnetization: the more positive, the more axial, the more negative, the more planar. We conclude from this benchmark that the fitting by a $A T^{-1}+C T^{-3}+E T^{-5}$ function provides parameters in reasonable agreement with the $a b$ initio ones.

The $\delta_{K}^{p}=f(1 / T)$ curves were fitted according to this procedure for protons $\mathrm{H} 3$ and $\mathrm{H} 4$ in the $\left[\mathrm{Np}^{\mathrm{VI}} \mathrm{O}_{2}(\mathrm{DPA})_{2}\right]^{2-}$ complex (see Table SI-7 and 9). One gets similar parameters for the two protons with a gap $\Delta$ of $305 \mathrm{~cm}^{-1} . \Delta g_{1}^{2}+\Delta g_{2}^{2}$ is found to be negative and the coupling $\Delta M_{12}^{2}$ important. The SO-RASPT2 with correlated $5 \mathrm{~d}$ and $5 \mathrm{p}$ orbitals is the only calculation in Table 8 that provides a negative value of $\Delta g_{1}^{2}+\Delta g_{2}^{2}$. This explains the good agreement between experiment and theory with SO-RASPT2*, temperature limit of Eq. 19. The Taylor expansion in terms of $x=$ $\beta \Delta=\Delta^{\prime} / \mathrm{T}\left(\Delta^{\prime}=\Delta / k_{B}\right)$ gives:

$$
\begin{aligned}
\delta_{K}^{p} & =\frac{10^{6} \mu_{0} \mu_{B}^{2}}{12 \pi k_{B}} G_{K}\left[\frac{\Delta g_{1}^{2}+\Delta g_{2}^{2}+4 \Delta M_{12}^{2}}{8 T}+\frac{\left(\Delta g_{1}^{2}-\Delta g_{2}^{2}\right) \Delta^{\prime}}{16 T^{2}}\right. \\
& \left.-\frac{\Delta M_{12}^{2} \Delta^{\prime 2}}{24 T^{3}}-\frac{\left(\Delta g_{1}^{2}-\Delta g_{2}^{2}\right) \Delta^{\prime 3}}{192 T^{4}}+\frac{\Delta M_{12}^{2} \Delta^{\prime 4}}{240 T^{5}}+\cdots\right]
\end{aligned}
$$

for the pNMR shift calculation. In Table SI- $8, \delta_{K}^{p}$ is decomposed in $T^{-n}$ contributions. The different contributions alternate in sign, the $T^{-1}$ one is the dominant one, the weight of the other ones strongly diminishes at $350 \mathrm{~K}$, but play a key role at $220 \mathrm{~K}$; for example the $T^{-3}$ term contributes for $80 \%$ of the total delta value for $\mathrm{H} 4$.

Table 9: Model parameters for the $\left[\mathrm{Pu}^{\mathrm{VI}} \mathrm{O}_{2}(D P A)_{2}\right]^{2-}$ complex evaluated from ab initio calculations or deduced by fitting the $\Delta \chi_{a x}$ and $\delta_{K}^{p}$ curves. $\Delta \mathrm{in} \mathrm{cm}^{-1}$.

\begin{tabular}{cccc} 
Method & & $\Delta$ & $g_{z}$ \\
\hline & {$\left[\mathrm{Pu}^{\mathrm{VI}} \mathrm{O}_{2}(\mathrm{DPA})_{2}\right]^{2-}$} & & \\
\hline SO-CASSCF & ab initio & 1 & 5.89 \\
SO-CASPT2 & ab initio & 61 & 5.70 \\
SO-CASPT2 & ab initio & 98 & 5.73 \\
SO-RASSCF & ab initio & 0.2 & 5.89 \\
SO-RASPT2 & ab initio & 8 & 5.85 \\
SO-RASPT2* & ab initio & 84 & 5.84 \\
& fit $\Delta \chi_{\text {ax }}{ }^{*}$ & 86 & 5.84 \\
& fit polynom & 66 & 5.79 \\
\hline pNMR shift H3 & Fit of the experimental curves & & \\
\hline pNMR shift H4 & fit polynom ${ }^{\#}$ & 58 & 5.3 \\
\hline
\end{tabular}

*: $5 \mathrm{~d}$ and $5 \mathrm{p}$ orbitals are correlated. $\%$ : Eq. 23 , T range: $250-350 \mathrm{~K}$.

\# : Eq. 25, T range: $250-350 \mathrm{~K}$.

$P u^{V I}$ complex. The temperature dependence of the pNMR chemical shifts for protons $\mathrm{H} 3$ and $\mathrm{H} 4$ in the $\left[\mathrm{Pu}^{\mathrm{VI}} \mathrm{O}_{2}(\mathrm{DPA})_{2}\right]^{2-}$ complex is represented in Figure 6 . It can be fitted using Eq. 22, with two parameters, $\Delta$ the energy splitting and $g_{z}^{2}$ the magnetic moment of the NKD. The fitting of the SORASPT2 $^{*}$ curve according to this equation in the room temperature window leads to values of $\Delta$ and $g_{z}^{2}$ in very good agreement with the ab initio ones (see Table 9). As previously for the $\mathrm{Np}^{\mathrm{VI}}$ complex, the experimental incertitude renders the fitting of the curves by Eq. 23 unfeasible and we considered the high temperature Taylor expansion of this equation terms of $x=\beta \Delta=$ $\Delta^{\prime} / \mathrm{T}$

$$
\delta_{K}^{p}=\frac{10^{6} \mu_{0} \mu_{B}^{2}}{12 \pi k_{B}} G_{K} g_{z}^{2}\left(\frac{1}{4 T}-\frac{\Delta^{\prime 2}}{48 T^{3}}+\frac{\Delta^{\prime 4}}{480 T^{5}}+\cdots\right)
$$

The $T^{-1}$ term is the Curie contribution for a doublet and higher orders are due to the splitting of the doublet $\Delta$. The fit of the $\delta_{K}^{p}=$ $f(1 / T)$ SO-RASPT2 curve by a $A T^{-1}+C T^{-3}$ function leads to an underestimated value of $\Delta$. The fitting of the experimental curves by Eq. 24 up to $T^{-3}$ leads to comparable value of $\Delta$. This is in favor of a splitting of the ground doublet in agreement with 
the SO-RASPT2* results. However, the $T^{-1}$ term is by far dominant and the $T^{-3}$ contributes for only $1 \%$ (see Table SI-9) while it is this latter term that provides the information on the energy gap; the determination of $\Delta$ from the $\delta_{K}^{p}=f(1 / T)$ curve should be taken with care.

\section{Conclusion}

The ${ }^{1} \mathrm{H}$ AIS shifts in $\left[\mathrm{Np}^{\mathrm{VI}} \mathrm{O}_{2}(\mathrm{DPA})_{2}\right]^{2-},\left[\mathrm{Np}^{\mathrm{VI}} \mathrm{O}_{2}(\mathrm{Et}-\mathrm{DPA})_{2}\right]^{2-}$, $\left[\mathrm{Pu}^{\mathrm{VI}} \mathrm{O}_{2}(\mathrm{DPA})_{2}\right]^{2-}$ and $\left[\mathrm{Pu}^{\mathrm{VI}} \mathrm{O}_{2}(\mathrm{Et}-\mathrm{DPA})_{2}\right]^{2-}$ complexes were characterized by NMR spectroscopy and magnetic susceptibility was measured by $\mathrm{NMR}$ on $\left[\mathrm{Np}^{\mathrm{VI}} \mathrm{O}_{2}(\mathrm{DPA})_{2}\right]^{2-}$ and $\mathrm{Pu}^{\mathrm{VI}} \mathrm{O}_{2}$ (Et $\left.\mathrm{DPA})_{2}\right]^{2-}$ complexes using the Evans method. In addition, the solid $\mathrm{Li}_{2} \mathrm{~Np}^{\mathrm{VI}} \mathrm{O}_{2}$ (DPA) $)_{2} \cdot 2 \mathrm{H}_{2} \mathrm{O}$ compound was characterized by SQUID susceptometry.

From the structures determined by $\mathrm{X}$-rays diffraction experiments, ${ }^{[30]}$ the analysis of the ${ }^{1} \mathrm{H}$ pNMR chemical shifts at the different positions of the DPA and Et - DPA ligands showed that the Fermi contact contribution to the chemical shifts is negligible, even for the protons close from the paramagnetic center. This is confirmed by the vanishing spin density on all hydrogen atoms as determined by unrestricted DFT. Accordingly, they were discussed in term of a pure dipolar interaction and the experimental $\Delta \chi_{a x}$ values were determined using $\mathrm{X}$-rays geometrical factors. Combined with Evans method which provides the isotropic average susceptibility $\chi_{m}$, the two components of the susceptibility tensor were calculated.

Wave function based calculations were performed in order to compute the electronic structure of the paramagnetic center. The $\mathrm{Np}^{\mathrm{VI}}$ complexes have two low lying $\mathrm{KDs}$ whose composition depends subtly on the level of calculation and the correlation of the $5 \mathrm{~d}$ and $5 \mathrm{p}$ orbitals play an important role. This dramatically impacts the magnetic properties, between other the axiality of the magnetization. In the solid $\mathrm{Li}_{2} \mathrm{~Np}^{\mathrm{VI}} \mathrm{O}_{2}(\mathrm{DPA})_{2} \cdot 2 \mathrm{H}_{2} \mathrm{O}$ compound, the $\mathrm{Li}^{+}$counterions are directly coordinated to the oxygen atoms of the coordination sphere and influence the magnetic properties of the paramagnetic center. In the presence of the $\mathrm{Li}^{+}$counterions, the ligand field is lower and the magnetic susceptibility larger, in agreement with the increase of the magnetic susceptibility between the SQUID and the NMR measurements in solution with Evans method. The $\mathrm{Pu}^{\mathrm{VI}}$ complexes have a well isolated ground NKD, with one electron in a $f_{\delta}$ and the other in a $f_{\phi}$ orbital. Magnetic properties depend barely on the level of calculation, except that a splitting of the doublet appears, and barely on the nature of the equatorial ligand.

The ${ }^{1} \mathrm{H}$ AIS in $\left[\mathrm{An}^{\mathrm{VI}} \mathrm{O}_{2}(\mathrm{DPA})_{2}\right]^{2-}$ and $\left[\mathrm{An}^{\mathrm{VI}} \mathrm{O}_{2}(\mathrm{Et}-\mathrm{DPA})_{2}\right]^{2-}$ complexes (with $\mathrm{An}^{\mathrm{VI}}=\mathrm{Np}^{\mathrm{VI}}$ and $\mathrm{Pu}{ }^{\mathrm{VI}}$ ) were evaluated using the $\Delta \chi_{a x}$ values obtained from ab initio calculations. For the $\mathrm{Np}^{\mathrm{VI}}$ cation, the proper description of its electronic structure is of great importance as it changes the amplitude but also the sign of the calculated pNMR chemical shifts. The two low lying KDs play a key role, and more specifically their magnetic coupling leading to a predominant Van Vleck contribution. The values issued from the SO-RASPT2 calculation are in good agreement with the experimental ones. On the contrary, the 2-component SO-ZORA method lacks both de spin polarization and the Van Vleck contribution. For the $\mathrm{Pu}^{\mathrm{vl}}$, the calculations slightly overestimate the $\Delta \chi_{a x}$ values and consequently the ${ }^{1} \mathrm{H}$ pseudocontact chemical shifts.

The temperature dependence of the average susceptibility and the pNMR chemical shifts is analyzed in terms of the generalized Van Vleck and Soncini equations, respectively. Those equations are very similar in their forms, the former probing the isotropic magnetic parameters while the latter probes the anisotropic ones. Those two equations are expressed in terms of the block matrices of the magnetic moment operator. This avoids the use of Spin Hamiltonians and allows for the modelling of molecular systems where the definition of a Spin Hamiltonian is not straightforward, in particular for actinide complexes. The reduction of Soncini equation to a restricted model space allows the fitting of the temperature dependence by few parameters.

The regression analysis of the $\delta_{K}^{p}=f(1 / T)$ curves evidence the predominance of the $T^{-1}$ term, in contradiction with Bleaney's model which assigns this term to the Fermi contact contribution. This model applies in lanthanide complexes because all the components of the ground $J$ manifold of the free ion are statically populated, giving rise to an isotropic magnetization. In actinyl cations, only some of those components are populated, the room temperature magnetization is anisotropic and the dipolar contribution to $T^{-1}$ term is proportional to the anisotropic magnetic moment of the paramagnetic center at room temperature. Further $T^{-n}$ terms depend on the energy gap, in the case of a two level system.

The experimental $\delta_{K}^{p}=f(1 / T)$ and $\chi_{m}=f(1 / T)$ are fitted according to the generalized Van Vleck and Soncini equation, respectively, within an axial symmetry and a reduced model space, either in its full form for the susceptibility or in its polynomial expansion for the chemical shifts. And this allows the determination of the energy gap and the magnetic moment, either isotropic from the susceptibility, or anisotropic from the chemical shifts. The fitted parameters are in good agreement with the $a b$ initio results. In the $\mathrm{Np}^{\mathrm{VI}}$ complex, the energy gap between the two KDs is about $300 \mathrm{~cm}^{-1}$, and the magnetization is oblate. This determination from a temperature curve provides only an estimation of the energy gap: it is shown that in the $a b$ initio case where the gap is known, the gap determined by the fitting procedure is underestimated by $10-20 \%$. For the $\mathrm{Pu}^{\mathrm{VI}}$ complex, the $\delta_{K}^{p}=f(1 / T)$ is an almost pure $T^{-1}$ term. The $T^{-3}$ participates for only $1 \%$ but its analysis is in favor of a splitting of about $50 \mathrm{~cm}$ ${ }^{1}$ of the ground doublet.

As well the pure dipolar interaction for ${ }^{1} \mathrm{H}$ nuclei as the insensitivity of the $\left[\mathrm{Pu}^{\mathrm{VI}} \mathrm{O}_{2}\right]^{2+}$ cation to the equatorial ligands are very promising in the goal to use $\left[\mathrm{An}^{\mathrm{VI}} \mathrm{O}_{2}\right]^{2+}$ cations as paramagnetic probe to get structural information. However, the predominance of the $T^{-1}$ term in the dipolar contribution renders the unraveling of Fermi contact and dipolar contributions through a temperature analysis more difficult. 


\section{Experimental Section}

Synthesis. Caution!!! ${ }^{238+235}$ Uranium, ${ }^{237}$ Neptunium and ${ }^{239+240}$ Plutonium are radioactive elements and have to be handled in dedicated facilities with appropriate equipment for radioactive materials. Their manipulation has been carried out at the ATALANTE facility (CEA-Marcoule, France). The experiments involving $\mathrm{Np}$ and $\mathrm{Pu}$ were performed in a regular air atmosphere negative pressure glove box with restrictive protocols, whereas $U$ was manipulated under fume hood.

2,6-dipicolinic acid ( $\left.\mathrm{H}_{2} \mathrm{DPA}\right)$, lithium hydroxide $(\mathrm{LiOH})$, silver +ll oxide $\left(\mathrm{Ag}^{\mathrm{II}} \mathrm{O}\right), \mathrm{HNO}_{3} 70 \%, \mathrm{HCl} 37 \%$ and tert-Butyl alcohol $(\mathrm{t}-\mathrm{BuOH})$ were purchased from Sigma-Aldrich. [D $\mathrm{D}_{6}$ DMSO (dimethyl sulfoxide) and $\left[\mathrm{D}_{7}\right] \mathrm{DMF}(\mathrm{N}, \mathrm{N}$-dimethylformamide) were purchased from Cortecnet or Eurisotop and used as received.

4-ethyl-2,6-dipicolinic acid ( $\mathrm{H}_{2} \mathrm{Et}$ - DPA) ligand was synthesized in the lab according to the protocol described by Shelkov. ${ }^{[51]} \mathrm{H}_{2} \mathrm{Et}-$ DPA purity was checked by ${ }^{1} \mathrm{H}$ NMR spectroscopy. ${ }^{1} \mathrm{H}$ NMR (400 MHz, [D $\left.\left.{ }_{6}\right] \mathrm{DMSO}\right): \delta(\mathrm{ppm})$ $7.76(\mathrm{~s}, 2 \mathrm{H}, \mathrm{H} 3), 2.65$ (q, J = $7.58 \mathrm{~Hz}, 2 \mathrm{H}, \mathrm{H} 5), 1.18$ (t, J = $7.58 \mathrm{~Hz}, 3 \mathrm{H}$, $\mathrm{H6)}$.

The initial uranium solution was $\mathrm{U}^{\mathrm{VI}}$ in 0.1 mol. $\mathrm{L}^{-1} \mathrm{HNO}_{3}$; a solution of $\mathrm{Np}^{\mathrm{V}}$ was prepared by dissolving solid $\mathrm{Np}^{\mathrm{V}} \mathrm{O}_{2} \mathrm{OH}$ in 1 mol. $\mathrm{L}^{-1} \mathrm{HNO}_{3}$; the initial plutonium solution was $\mathrm{Pu}^{\mathrm{IV}}$ in 1 mol. $\mathrm{L}^{-1} \mathrm{HNO}_{3} \cdot \mathrm{Np}^{\mathrm{V}}$ and $\mathrm{Pu}^{\mathrm{IV}}$ were oxidized by adding $\mathrm{Ag}^{\mathrm{II}} \mathrm{O}$ (molar ratio $\mathrm{Np}^{\mathrm{V}} / \mathrm{Ag}^{\mathrm{II}} \mathrm{O}$ of $1 / 5$ and molar ratio $\mathrm{Pu}^{\mathrm{IV}} / \mathrm{Ag}^{\mathrm{II}} \mathrm{O}$ of $1 / 10$ ) to prepare $\mathrm{Np}^{\mathrm{VI}}$ and $\mathrm{Pu}^{\mathrm{VI}}$ nitrate solutions. Oxidation states and concentrations of actinide solutions were checked by visibleNIR spectrophotometry (Agilent Cary 5000 spectrophotometer). AgCl was precipitated subsequently by adding a stoichiometric amount of $\mathrm{HCl}$ and the resulting white solid was removed by centrifugation.

Solid $\mathrm{Li}_{2} \mathrm{An}^{\mathrm{VI}} \mathrm{O}_{2}$ (DPA $)_{2} \cdot 2 \mathrm{H}_{2} \mathrm{O}$ compounds with $\mathrm{An}^{\mathrm{VI}}=\mathrm{U}^{\mathrm{VI}}, \mathrm{Np}^{\mathrm{VI}}$ and $\mathrm{Pu}^{\mathrm{VI}}$ were prepared from aqueous $\mathrm{An}^{\mathrm{VI}} \mathrm{O}_{2}^{2+}$ solutions by adapting a synthesis developed by Yusov et al. in 2013. ${ }^{[30]}$ The initial $\mathrm{An}^{\mathrm{VI}} / \mathrm{H}_{2} \mathrm{DPA}$ (with a molar ratio of $1 / 5$ ) mixtures in nitric acid were progressively brought up to $\mathrm{pH} 6$ by adding $\mathrm{LiOH}$ under stirring. The precipitates were washed twice with water and ethanol then dried at room temperature under $\mathrm{N}_{2}$ flow. The same experimental procedure was applied to synthesize $\mathrm{Li}_{2} \mathrm{An}^{\mathrm{VI}} \mathrm{O}_{2}(\mathrm{Et}-$ DPA $)_{2} \cdot \mathrm{xH}_{2} \mathrm{O}$ compounds with $\mathrm{An}^{\mathrm{VI}}=\mathrm{U}^{\mathrm{VI}}, \mathrm{Np}^{\mathrm{VI}}$ and $\mathrm{Pu}^{\mathrm{VI}}$

Powder XRD. Powder XRD patterns were recorded on a Bruker D8 Advance diffractometer equipped with a LynxEye detector in BraggBrentano geometry using $\mathrm{Cu}$ Ka1,2 radiation $(\mathrm{Ka} 1=1.5406 \AA$; $\mathrm{Ka} 2=$ $1.5444 \AA$ ). The scan step was fixed to $0.02^{\circ}$ with a counting time of 1 s.step ${ }^{-1}$ from $5^{\circ}$ to $60^{\circ}$. Silicon was added to samples as an internal standard to calibrate the angular positions of the observed XRD lines. The $\mathrm{Li}_{2} \mathrm{An}^{\mathrm{VI}} \mathrm{O}_{2}$ (DPA) $2 \cdot 2 \mathrm{H}_{2} \mathrm{O}$ compounds and silicon were mixed with an epoxy resin to prevent contamination spreading as the diffractometer is outside glove box. Ka2 stripping of the $\mathrm{Cu}$ radiation according to the Rachinger method, as well as the baseline and angle shift corrections, were performed by empirical calculations and EVA software. ${ }^{[52]}$ All powder patterns were refined thoroughly by the Profile matching method using FullProf Suite. ${ }^{[53]}$ During the refinement, the following parameters were allowed to vary: zero shift, scale factors, lattice parameters, and profile parameters (including asymmetry). Two phases were considered for the refinement: $\mathrm{Li}_{2} \mathrm{An}^{\mathrm{VI}} \mathrm{O}_{2}$ (DPA) $)_{2} \cdot 2 \mathrm{H}_{2} \mathrm{O}$ structures reported by Yusov et al. ${ }^{[30]}$ and the silicon standard phase.

NMR spectroscopy. ${ }^{1} \mathrm{H}$ NMR spectra were recorded at $298 \mathrm{~K}$ using a $400 \mathrm{MHz}$ Fourier transform spectrometer, Agilent DD2, set up for the study of radioactive samples. ${ }^{[54]}$ Acquisition and processing were performed with VnmrJ 2.4 software (Available at: http://github.com/OpenVnmrJ). NMR samples were prepared by dissolving $\mathrm{Li}_{2} \mathrm{An}^{\mathrm{VI}} \mathrm{O}_{2}(\mathrm{DPA})_{2} \cdot 2 \mathrm{H}_{2} \mathrm{O}$ and $\mathrm{Li}_{2} \mathrm{An}^{\mathrm{VI}} \mathrm{O}_{2}(\mathrm{Et}-\mathrm{DPA})_{2} \cdot \mathrm{xH}_{2} \mathrm{O}$ solid compounds in $\left[\mathrm{D}_{7}\right] \mathrm{DMF}$. For
$\left[\mathrm{An}^{\mathrm{VI}} \mathrm{O}_{2}(\mathrm{DPA})_{2}\right]^{2-}$ complexes, the spectra were also collected at every 10 $\mathrm{K}$ step on the temperature range $220-350 \mathrm{~K}$.

Magnetic susceptibility *with NMR spectroscopy. The molar magnetic susceptibility $\chi_{m}^{\text {Evans }}$ of $\left[\mathrm{Np}^{\mathrm{VI}} \mathrm{O}_{2}(\mathrm{DPA})_{2}\right]^{2-}$ and $\left[\mathrm{Pu}^{\mathrm{VI}} \mathrm{O}_{2}\right.$ (Et $\left.\mathrm{DPA})_{2}\right]^{2-}$ in $\left[\mathrm{D}_{7}\right] \mathrm{DMF}$ was calculated from the chemical shift difference $\Delta \delta$ between ${ }^{1} \mathrm{H}$ NMR signal of working $\left(t-\mathrm{BuOH}_{\text {in }}\right)$ and reference $\left(t-\mathrm{BuOH}_{\text {out }}\right)$ solutions using Evans method. [44] The $\mathrm{t}-\mathrm{BuOH}$ concentration used for these experiments was $0.1 \mathrm{~mol} \mathrm{~L}^{-1}$.

$$
\chi_{m}^{\text {Evans }}=\frac{3 \Delta \delta}{10^{3}\left[\mathrm{An}^{\mathrm{VI}}\right]}
$$

where $\Delta \delta$ is dimensionless, [ $\mathrm{An}{ }^{\mathrm{VI}}$ ] is the molar concentration $\left(\mathrm{mol} \mathrm{L}^{-1}\right)$ of the paramagnetic element and $\chi_{m}^{\text {Evans }}$ is the molar magnetic susceptibility $\left(\mathrm{m}^{3} \mathrm{~mol}^{-1}\right)$. Uncertainties values were estimated by taking into account $\Delta \delta$ accuracies of NMR spectra and concentration measurements using $\mathrm{Y}$ and a counting.

*with a SQUID magnetometer. A MPMS3 magnetometer dedicated to radioactive sample analysis was used. Experiments were performed on the $\mathrm{Li}_{2} \mathrm{An}^{\mathrm{VI}} \mathrm{O}_{2}(\mathrm{DPA})_{2} \cdot 2 \mathrm{H}_{2} \mathrm{O}$ solid compound on the temperature range $2-$ $300 \mathrm{~K}$.

\section{Computational details}

Geometry optimization. The geometry calculations were performed with Gaussian09 ${ }^{[55]}$ within the density functional theory (DFT) framework using the PBE functional. ${ }^{[56]}$ For uranium, a small core relativistic effective core potential (RECP-60 electrons with the corresponding TZ basis set ${ }^{[57-}$ 58] by the Stuttgart-Cologne group was used and the def-TZVP basis set ${ }^{[59]}$ was used for the other atoms. Solvent effects were included implicitly with a polarizable continuum model. All the optimized geometries were checked to be true minima by a frequency calculation.

Electronic properties. All wave function based calculations have been performed on the crystallographic structures with the MOLCAS 7.8 suite of software ${ }^{[60]}$ following the CASSCF/CASPT2/SO-RASSI scheme. First, CASSCF (Complete Active Space Self Consistent Field) calculations [61] were performed with an active space of six f-orbitals and associated electrons (n) i.e. CAS $(n, 6)$. An extended active space was considered using the RASSCF (Restricted Active Space Self Consistent Field) scheme; the 6 (anti) bonding sigma and pi orbitals of the yle bonds were included in RAS1 (RAS3) allowing 2 holes (particles). ${ }^{[62-63]}$ The dynamica correlation was added with the CASPT2 (Complete Active Space Perturbation Theory at $2^{\text {nd }}$ order $)^{[64]}$ method using the CASSCF or RASSCF reference states [65] without any level shift. Relativistically contracted ANO (Atomic natural Orbitals) basis sets [66-67] were used for the calculations with TZP quality for $\mathrm{Np}, \mathrm{Pu}, \mathrm{N}, \mathrm{O}$ and $\mathrm{Li}$; DZP for $\mathrm{C}$ and DZ for $\mathrm{H}$ atoms. Douglas Kroll Hess (DKH2) ${ }^{[68-69]}$ transformed Hamiltonian was used to treat the relativistic effects for both scalar (SR) and spin-orbit (SO). 6 doublets were taken for the $\mathrm{Np}^{\mathrm{VI}}$ complex and 15 triplets and 21 singlets for the $\mathrm{Pu}^{\mathrm{VI}}$ complex, reduced to 8 triplets and 14 singlets in case of RASPT2. SO coupling was calculated as a state interaction either with CASSCF or RASSCF wave functions and corresponding energies leading to the so-called SO-CASSCF and SO-RASSCF results, or with MS CASPT2 or MS-RASPT2 wave functions and corresponding energies leading to the so-called SO-CASPT2 and SO-RASPT2. SO matrix elements were computed using the one center approximation AMFI (Atomic Mean Field Integrals) ${ }^{[70]}$ and $g$ factors were calculated according to ref. [71]. Spin densities were determined from unrestricted DFT calculations with the PBEO functional and ANO-RCC basis sets of TZP quality on all atoms and a fractional occupation of the $5 f$ orbitals $(1 \mathrm{e} / 2 \mathrm{e}$ in 4 orbitals for the $\mathrm{Np} \mathrm{VI}^{\mathrm{VI}} \mathrm{Pu}^{\mathrm{VI}}$ complex) 
2-component DFT calculations were carried out with the Amsterdam Density Functional (ADF) program on the $\mathrm{Np}^{\mathrm{VI}}$ complex using hybrid PBE0 functional ${ }^{[72]}$ with the all-electron doubly polarized triple- $\zeta^{2}$ (TZ2P) ${ }^{[73]}$ basis for the metal and 'jcpl' augmented version ${ }^{[74]}$ of TZ2P for N, O, C and $\mathrm{H}$. Relativistic effects were introduced both at $\mathrm{SR}$ and SO level with the ZORA (Zeroth Order Regular Approximation) all-electron relativistic Hamiltonian. ${ }^{[75]}$ First, a scalar relativistic calculation was performed and then magnetic properties ( $g$-values, hyperfine values) were calculated with the ESR ${ }^{[76-77]}$ module of ADF. In the ESR module, effects of SO coupling are treated self consistently with the two-component relativistic SO-ZORA Hamiltonian using spin-restricted formalism. Although this restricted formalism does not allow for the evaluation of spin polarization effects, in case of one unpaired electron and very large effects of SO coupling, the spin-restricted calculation may be of interest, since it uses KDs exactly related by time-reversal symmetry. ${ }^{[78]}$

\section{Acknowledgements}

Fruitful discussions with Jochen Autschbach and Dumitru-Claudiu Sergentu are acknowledged. This work was supported by the French ANR under convention $\mathrm{N}^{\circ}$ ANR-17-CE06-0010. The access to the JRC-Karlsruhe infrastructure through the Actinide User Laboratory program (Project AUL-196) of the European Commission is acknowledged. This work was performed using HPC resources from GENCI-IDRIS (Grant 2019- 101034). JH beneficiated from the support of Erasmus+ program of the European Union.

Keywords: actinide $\cdot$ paramagnetic NMR spectroscopy $\bullet S Q$ Bleaney's theory $\cdot a b$ initio calculations

[1] J. A. Peters, J. Huskens, D. J. Raber, Prog. Nucl. Magn. Reson. Spectrosc. 1996, 28, 283-350.

[2] I. Bertini, C. Luchinat, Coord. Chem. Rev. 1996, 150, 29-75.

[3] M. Clore, J. Potts, Recent Developments in Biomolecular NMR, The Royal Society of Chemistry, Cambridge, 2012.

[4] E. Ravera, G. Parigi, C. Luchinat, J. Magn. Reson. 2019, 306, 173-179.

[5] C. Adam, B. B. Beele, A. Geist, U. Müllich, P. Kaden, P. J. Panak, Chem. Sci. 2015, 6, 1548-1561.

[6] C. Adam, P. Kaden, B. B. Beele, U. Müllich, S. Trumm, A. Geist, P. J. Panak, M. A. Denecke, Dalton Trans. 2013, 42, 14068-14074.

[7] M. Autillo, L. Guerin, T. Dumas, M. S. Grigoriev, A. M. Fedoseev, S. Cammelli, P. L. Solari, D. Guillaumont, P. Guilbaud, P. Moisy, H. Bolvin, C. Berthon, Chem. - Eur. J. 2019, 25, 4435-4451.

[8] F. Gendron, J. Autschbach, J. Chem. Theory Comput. 2016, 12, 53095321

[9] F. Gendron, K. Sharkas, J. Autschbach, J. Phys. Chem. Lett. 2015, 6 2183-2188.

[10] L. Martel, N. Magnani, J.-F. Vigier, J. Boshoven, C. Selfslag, I. Farnan, J.C. Griveau, J. Somers, T. Fanghänel, Inorg. Chem. 2014, 53, 6928-6933.

[11] D. L. Clark, D. E. Hobart, M. P. Neu, Chem. Rev. 1995, 95, 25-48.

[12] G. R. Choppin, M. P. Jensen, in The Chemistry of the Actinide and Transactinide Elements (Eds.: L. R. Morss, N. M. Edelstein, J. Fuger), Springer Netherlands, Dordrecht, 2006, pp. 2524-2621

[13] R. J. Kurland, B. R. McGarvey, J. Magn. Reson. (1969) 1970, 2, 286-301.

[14] I. Bertini, C. Luchinat, G. Parigi, Prog. Nucl. Magn. Reson. Spectrosc. 2002, 40, 249-273.

[15] C. N. Reilley, B. W. Good, R. D. Allendoerfer, Anal. Chem. 1976, 48, 1446-1458.

[16] C. N. Reilley, B. W. Good, J. F. Desreux, Anal. Chem. 1975, 47, 2110 2116.

[17] B. Bleaney, J. Magn. Reson. 1972, 8, 91-100.

[18] B. Bleaney, C. M. Dobson, B. A. Levine, R. B. Martin, R. J. P. Williams, A. V. Xavier, J. Chem. Soc., Chem. Commun. 1972, 791b-793.

[19] R. M. Golding, M. P. Halton, Aust. J. Chem. 1972, 25, 2577-2581.

[20] R. M. Golding, P. Pyykkö, Mol. Phys. 1973, 26, 1389-1396.

[21] A. A. Pinkerton, M. Rossier, S. Spiliadis, J. Magn. Reson. (1969) 1985, $64,420-425$.

[22] G. Castro, M. Regueiro-Figueroa, D. Esteban-Gómez, P. Pérez-Lourido, C. Platas-Iglesias, L. Valencia, Inorg. Chem. 2016, 55, 3490-3497.
[23] E. A. Suturina, K. Mason, C. F. G. C. Geraldes, I. Kuprov, D. Parker, Angew. Chem., Int. Ed. 2017, 56, 12215-12218.

[24] E. W. Stout, H. S. Gutowsky, J. Magn. Reson. (1969) 1976, 24, 389-398.

[25] B. R. McGarvey, J. Magn. Reson. (1969) 1979, 33, 445-455.

[26] A. D. Sherry, P. P. Yang, L. O. Morgan, J. Am. Chem. Soc. 1980, 102, 5755-5759.

[27] F. Gendron, B. Pritchard, H. Bolvin, J. Autschbach, Inorg. Chem. 2014, 53, 8577-8592.

[28] J. A. Peters, K. Djanashvili, C. F. G. C. Geraldes, C. Platas-Iglesias, Coord. Chem. Rev. 2020, 406, 213146.

[29] J. F. Desreux, C. N. Reilley, J. Am. Chem. Soc. 1976, 98, 2105-2109.

[30] A. B. Yusov, V. I. Mishkevich, A. M. Fedoseev, M. S. Grigor'ev, Radiochemistry 2013, 55, 269-278.

[31] S. Moon, S. Patchkovskii, in Calculation of NMR and EPR Parameters: Theory and Applications, Wiley-VCH ed., Weinheim, 2004, pp. 325-338.

[32] Z. Rinkevicius, J. Vaara, L. Telyatnyk, O. Vahtras, J. Chem. Phys. 2003 118, 2550-2561.

[33] P. Hrobárik, R. Reviakine, A. V. Arbuznikov, O. L. Malkina, V. G. Malkin, F. H. Köhler, M. Kaupp, J. Chem. Phys. 2007, 126, 024107.

[34] F. Rastrelli, A. Bagno, Chem. - Eur. J. 2009, 15, 7990-8004.

[35] S. A. Rouf, J. Mareš, J. Vaara, J. Chem. Theory Comput. 2015, 11, 16831691.

[36] J. Autschbach, S. Patchkovskii, B. Pritchard, J. Chem. Theory Comput. 2011, 7, 2175-2188.

[37] J. T. Coutinho, M. A. Antunes, L. C. J. Pereira, H. Bolvin, J. Marçalo, M. Mazzanti, M. Almeida, Dalton Trans. 2012, 41, 13568-13571.

[38] D. P. Hernández, H. Bolvin, J. Electron Spectrosc. Relat. Phenom. 2014, 194, 74-80.

[39] M. Autillo, L. Guerin, D. Guillaumont, P. Moisy, H. Bolvin, C. Berthon, Inorg. Chem. 2016, 55, 12149-12157.

[40] H. M. McConnell, R. E. Robertson, J. Chem. Phys. 1958, 29, 1361-1365.

[41] B. R. McGarvey, Inorg. Chim. Acta 1998, 272, 43-54

[42] W. V. d. Heuvel, A. Soncini, J. Chem. Phys. 2013, 138, 054113.

[43] B. Martin, J. Autschbach, J. Chem. Phys. 2015, 142, 054108.

[44] D. F. Evans, J. Chem. Soc. 1959, 2003-2005.

[45] M. Vonci, K. Mason, E. A. Suturina, A. T. Frawley, S. G. Worswick, I. Kuprov, D. Parker, E. J. L. McInnes, N. F. Chilton, J. Am. Chem. Soc 2017, 139, 14166-14172.

[46] K. Mason, A. C. Harnden, C. W. Patrick, A. W. J. Poh, A. S. Batsanov, E. A. Suturina, M. Vonci, E. J. L. McInnes, N. F. Chilton, D. Parker, Chem. Commun. 2018, 54, 8486-8489.

[47] D. Parker, E. A. Suturina, I. Kuprov, N. F. Chilton, Acc. Chem. Res. 2020, 53, 1520-1534.

[48] K. Pierloot, E. v. Besien, J. Chem. Phys. 2005, 123, 204309

[49] F.-P. Notter, S. Dubillard, H. Bolvin, J. Chem. Phys. 2008, 128, 164315

[50] F. Gendron, D. Páez-Hernández, F.-P. Notter, B. Pritchard, H. Bolvin, J. Autschbach, Chem. - Eur. J. 2014, 20, 7994-8011

[51] R. Shelkov, A. Melman, Eur. J. Org. Chem. 2005, 2005, 1397-1401.

[52] DIFFRACplus EVA, Bruker Analytical X-ray Systems: Karlsruhe, Germany, 2007

[53] C. Frontera, J. Rodríguez-Carvajal, Phys. B (Amsterdam, Neth.) 2003, 335, 219-222.

[54] I. Farnan, C. Berthon, in Nuclear Magnetic Resonance: Volume 45, Vol. 45, The Royal Society of Chemistry, 2016, pp. 96-141.

[55] M. J. Frisch, G. W. Trucks, H. B. Schlegel, G. E. Scuseria, M. A. Robb, J. R. Cheeseman, G. Scalmani, V. Barone, G. A. Petersson, H. Nakatsuji, X Li, M. Caricato, A. V. Marenich, J. Bloino, B. G. Janesko, R. Gomperts, B. Mennucci, H. P. Hratchian, J. V. Ortiz, A. F. Izmaylov, J. L. Sonnenberg, D. Williams-Young, F. Ding, F. Lipparini, F. Egidi, J. Goings, B. Peng, A Petrone, T. Henderson, D. Ranasinghe, V. G. Zakrzewski, J. Gao, N. Rega, G. Zheng, W. Liang, M. Hada, M. Ehara, K. Toyota, R. Fukuda, J. Hasegawa, M. Ishida, T. Nakajima, Y. Honda, O. Kitao, H. Nakai, T. Vreven, K. Throssell, J. A. Montgomery, Jr., J. E. Peralta, F. Ogliaro, M. J. Bearpark, J. J. Heyd, E. N. Brothers, K. N. Kudin, V. N. Staroverov, T. A. Keith, R. Kobayashi, J. Normand, K. Raghavachari, A. P. Rendell, J. C. Burant, S. S. lyengar, J. Tomasi, M. Cossi, J. M. Millam, M. Klene, C. Adamo, R. Cammi, J. W. Ochterski, R. L. Martin, K. Morokuma, O. Farkas, J. B. Foresman, D. Fox, Gaussian 09, Revision D.01, 2013

[56] J. P. Perdew, K. Burke, M. Ernzerhof, Phys. Rev. Lett. 1996, 77, $3865-$ 3868.

[57] X. Y. Cao, M. Dolg, J. Mol. Struct.: THEOCHEM 2004, 673, 203-209.

[58] X. Y. Cao, M. Dolg, H. Stoll, J. Chem. Phys. 2003, 118, 487-496.

[59] A. Schafer, C. Huber, R. Ahlrichs, J. Chem. Phys. 1994, 100, 5829-5835.

[60] F. Aquilante, J. Autschbach, R. K. Carlson, L. F. Chibotaru, M. G. Delcey, L. De Vico, I. Fdez. Galván, N. Ferré, L. M. Frutos, L. Gagliardi, M. Garavelli, A. Giussani, C. E. Hoyer, G. Li Manni, H. Lischka, D. Ma, P. Å. Malmqvist, T. Müller, A. Nenov, M. Olivucci, T. B. Pedersen, D. Peng, F. Plasser, B. Pritchard, M. Reiher, I. Rivalta, I. Schapiro, J. Segarra-Martí, M. Stenrup, D. G. Truhlar, L. Ungur, A. Valentini, S. Vancoillie, V. Veryazov, V. P. Vysotskiy, O. Weingart, F. Zapata, R. Lindh, J. Comput. Chem. 2016, 37, 506-541.

[61] B. O. Roos, P. R. Taylor, P. E. M. Sigbahn, Chem. Phys. 1980, 48, 157 173. 
[62] K. Sharkas, B. Pritchard, J. Autschbach, J. Chem. Theory Comput. 2015, $11,538-549$

[63] J. Novotný, D. Přichystal, M. Sojka, S. Komorovsky, M. Nečas, R. Marek, Inorg. Chem. 2018, 57, 641-652.

[64] K. Andersson, P. A. Malmqvist, B. O. Roos, A. J. Sadlej, K. Wolinski, J. Phys. Chem. 1990, 94, 5483-5488.

[65] V. Sauri, L. Serrano-Andrés, A. R. M. Shahi, L. Gagliardi, S. Vancoillie, K. Pierloot, J. Chem. Theory Comput. 2011, 7, 153-168.

[66] B. O. Roos, R. Lindh, P.-Å. Malmqvist, V. Veryazov, P.-O. Widmark, J. Phys. Chem. A 2004, 108, 2851-2858.

[67] B. O. Roos, R. Lindh, P.-Å. Malmqvist, V. Veryazov, P.-O. Widmark Chem. Phys. Lett. 2005, 409, 295-299.

[68] M. Douglas, N. M. Kroll, Ann. Phys. 1974, 82, 89-155.

[69] B. A. Hess, Phys. Rev. A 1986, 33, 3742-3748.

[70] B. A. Heß, C. M. Marian, U. Wahlgren, O. Gropen, Chem. Phys. Lett. 1996, 251, 365-371.

[71] H. Bolvin, ChemPhysChem 2006, 7, 1575-1589.

[72] M. Ernzerhof, G. E. Scuseria, J. Chem. Phys. 1999, 110, 5029-5036.

[73] E. Van Lenthe, E. J. Baerends, J. Comput. Chem. 2003, 24, 1142-1156.

[74] S. Moncho, J. Autschbach, J. Chem. Theory Comput. 2010, 6, 223-234.

[75] E. v. Lenthe, E. J. Baerends, J. G. Snijders, J. Chem. Phys. 1993, 99 4597-4610.

[76] E. van Lenthe, A. van der Avoird, P. E. S. Wormer, J. Chem. Phys. 1998, 108, 4783-4796.

[77] E. van Lenthe, P. E. S. Wormer, A. van der Avoird, J. Chem. Phys. 1997, $107,2488-2498$

[78] D.-C. Sergentu, F. Gendron, J. Autschbach, Chem. Sci. 2018, 9, 62926306. 


\section{Entry for the Table of Contents}


The temperature dependence of ${ }^{1} \mathrm{H}$ pNMR chemical shifts are measured and modelled in the $\mathrm{An}^{\mathrm{VI}} \mathrm{O}_{2}^{2+}-\mathrm{DPA}$ complexes. Only the pseudocontact term is non zero. The magnetic susceptibility tensor, the energy states and magnetic moments of the paramagnetic center are deduced and compared to the SO-CASPT2 values. 